\title{
Changes in the rumen and colon microbiota and effects of live yeast dietary supplementation during the transition from the dry period to lactation of dairy cows
}

\author{
A. Bach, ${ }^{1,2 *}$ A. López-García, ${ }^{3}$ O. González-Recio,${ }^{3,4}$ G. Elcoso,${ }^{5}$ F. Fàbregas,${ }^{2}$ F. Chaucheyras-Durand,,${ }^{6,7}$ \\ and M. Castex \\ ${ }^{1}$ Institució Catalana de Recerca i Estudis Avançats (ICREA), 08010 Barcelona, Spain \\ ${ }^{2}$ Department of Ruminant Production, Institut de Recerca i Tecnologia Agroalimentàries (IRTA), 08140 Caldes de Montbui, Spain \\ ${ }^{3}$ Departamento de Mejora Genética Animal, Instituto Nacional de Investigación y Tecnología Agraria y Alimentaria (INIA), 28040 Madrid, Spain \\ ${ }^{4}$ Escuela Técnica Superior de Ingeniería Agronómica, Alimentaria y de Biosistemas, Universidad Politécnica de Madrid (UPM), \\ 28040 Madrid, Spain \\ ${ }^{5}$ Blanca from the Pyrenees, 25795 Hostalets de Tost, Spain \\ ${ }^{6}$ Université Clermont Auvergne, Unité de Recherche Microbiologie (UMR454 MEDIS), Institut National de la Recherche Agronomique \\ (INRA-UCA), 63000 Clermont-Ferrand, France \\ 'Lallemand Animal Nutrition, SAS, 19 Rue des Briquetiers, 31702 Blagnac, France
}

\section{ABSTRACT}

The first objective of this study was to evaluate the dynamics and their potential association with animal performance of the microbiota in both the rumen and colon of dairy cows as they move from a nonlactation to a lactation ration. The second objective was to assess the potential effects on the microbiota of live yeast supplementation. Twenty-one Holstein cows were split in 2 treatments consisting of $1 \times 10^{10} \mathrm{cfu} / \mathrm{d}$ of live yeast $(\mathrm{LY} ; \mathrm{n}=10)$ or no supplementation (control; $\mathrm{n}=11$ ) starting $21 \mathrm{~d}$ before until $21 \mathrm{~d}$ after calving. At $14 \mathrm{~d}$ before and 7 and $21 \mathrm{~d}$ after calving, samples of rumen and colon digesta were obtained from each cow using an endoscope. Total DNA was extracted and submitted to high-throughput sequencing. Shannon diversity index, in both the rumen and colon, was unaffected by LY; however, in the rumen it was lowest $7 \mathrm{~d}$ after calving and returned to precalving values at $21 \mathrm{~d}$ in milk, whereas in the colon it was greatest $14 \mathrm{~d}$ before calving but decreased after calving. In the rumen, LY supplementation increased the relative abundance (RA) of Bacteroidales (group UCG-001), Lachnospiracea (groups UCG-002 and UCG-006), and Flexilinea 14 d before calving, and increased RA of Streptococcus 21 d after calving compared with control cows. However, changes in the ruminal microbiota were more drastic across days relative to calving than as influenced by the dietary treatment, and the effect of LY in the colon was milder than in the rumen. The ruminal RA of several genera was associated with postcalving DMI, and that of Gastranaerophilales was the only order positively associated with milk yield. Several genera were positively correlated with feed efficiency, with Clostridiales (unclassified) being the only genus negatively associated with feed efficiency. In the colon, Prevotellaceae (group Ga6A1) was the only genus positively associated with feed efficiency. The ruminal RA of Prevotella 7 and Ruminobacter $14 \mathrm{~d}$ precalving was negatively correlated with dry matter intake and milk yield postcalving. The RA of Parabacteroides in the colon $14 \mathrm{~d}$ before calving was negatively correlated with milk yield, whereas the RA of Eggerthellaceae (unclassified) and Erysipelotrichaceae (groups c and unclassified) were positively correlated with feed efficiency. Interestingly, LY supplementation doubled the RA of Eggerthellaceae (unclassified) in the colon. It is concluded that microbial diversity in the rumen experiences a transient reduction after calving, whereas in the colon, the reduction is maintained at least until $21 \mathrm{~d}$ in milk. Most of the effects of LY on rumen microbiota were observed before calving, whereas in the colon, LY effects were more moderate but consistent and independent of the stage of production. The microbial community of the rumen after calving is more associated with feed intake, milk yield, and feed efficiency than that of the colon. However, the colon microbiota before calving is more associated with feed efficiency after calving than that of the rumen.

Key words: colon, endoscope, microbiota, rumen

\section{INTRODUCTION}

Received December 5, 2018.

Accepted March 12, 2019.

*Corresponding author: alex.bach@icrea.cat

During the production cycle, dairy cows are exposed to different rations and consume different volumes of 
feed. When cows are dry, typically during the last 60 $\mathrm{d}$ of pregnancy, they are fed rations high in fiber and containing a relative low energy density, whereas when lactating the proportion of fiber in the ration can easily be halved from that fed during the dry period and the energy density is typically increased by $25 \%$ (NRC, 2001). In addition, the amount of feed consumed by dry and lactating cows differs substantially, with the latter consuming around twice as much as dry cows. During the transition from a nonlactating to a lactating state the ration changes immediately after calving, but the change in feed consumption increases progressively during the few days following parturition.

It is well established that the type and amount of forage and concentrate that cows consume influence the rumen microbial composition (Nagaraja and Titgemeyer, 2007; Fernando et al., 2010), rumen microbial activity (Bach et al., 1999), and overall rumen environment. On the other hand, supplementing dairy rations with live yeast has been reported to induce changes in rumen $\mathrm{pH}$, microbial population, and fiber fermentation (Chaucheyras-Durand et al., 2008; Terré et al., 2015; Jiang et al., 2017b), and supplementing live yeast during the transition period could represent an effective strategy to prevent rumen dysfunctions after calving (Jouany, 2006). Therefore, it is likely that live yeast supplementation may exert some effects on the rumen by altering the microbiota, the ruminal environment, or both. Several studies have shown that live yeast supplemented through the diet can survive throughout the digestive tract of both sheep (Durand-Chaucheyras et al., 1998) and cattle (Fomenky et al., 2017) and can be recovered viable in the feces (in the range between 17 to $34 \%$ ), thus we hypothesize that live yeast might also exert a direct effect on the large intestine of cows. However, to the best of our knowledge little is known about what microbial populations in the rumen change with live yeast supplementation around transition in dairy cattle and even less is known about the potential effects of live yeast supplementation on the microbiota of the large intestine. Some studies describe the main changes in the rumen microbiota between 3 wk before and 3 wk after calving at the phylum (Pitta et al., 2014) and genus level (Zhu et al., 2018), and some others have attempted to establish relationships between rumen microbiota and production traits (Lima et al., 2015; Jiang et al., 2017a), but none has looked at the hindgut.

Herein we used endoscopy to collect digesta samples from the rumen and colon of cows with the objective of examining changes in the microbiota in these locations as they transition from a dry to a lactation ration. We also evaluate the potential influence of live yeast supplementation on the microbial community, and the potential associations between the rumen and the colon microbiota and productive traits early in lactation.

\section{MATERIALS AND METHODS}

All procedures used herein were conducted under the approval and supervision of the Ethical Committee of the Institut de Recerca i Tecnologia Agroalimentàries. Twenty-one dry Holstein cows (706 $\pm 85 \mathrm{~kg}$ of BW) that finished their first lactation were split in 2 treatment groups and received either $300 \mathrm{~g} / \mathrm{d}$ of corn containing $3.3 \mathrm{~g} / \mathrm{kg}$ (equivalent to $1 \times 10^{10} \mathrm{cfu} / \mathrm{d}$ ) of live yeast (Saccharomyces cerevisiae CNCM I-1077; Lallemand SAS, Blagnac, France; LY; $\mathrm{n}=10$ ) or $300 \mathrm{~g} / \mathrm{d}$ of corn with no supplementation (control; $\mathrm{n}=11$ ) starting 21 $\mathrm{d}$ before calving (259 d pregnant) until $21 \mathrm{~d}$ of lactation. The dose of $1 \times 10^{10} \mathrm{cfu} / \mathrm{d}$ was chosen because this is the amount commonly fed under commercial conditions, the dose registered in the European Union, and the dose shown to have positive effects on animal performance in a previous meta-analysis (De Ondarza et al., 2010). At each production stage (dry or lactating), the 2 groups of cows (control or LY) consumed the same diet with the only difference being the presence or absence of LY. Diets were sampled fortnightly and analyzed for DM (ID 934.01), ash (ID 942.05), N (ID 984.13), and ether extract (ID 920.39) content following the methods from the Association of Official Analytical Chemists (AOAC, 1999). Neutral detergent fiber determination was performed according to Van Soest et al. (1991). The ingredient and nutrient composition of the dry and the lactation rations is depicted in Table 1. Dry cows were housed in group pens with ad libitum access to water and feed and were bedded with straw. Lactating cows were housed in freestalls and the 2 treatment groups were kept in the same pen. Individual feed intake of lactating cows was monitored on a daily basis using electronic scales with controlled individual access for each cow to specific feed bins using a radio-frequency identification system described elsewhere (Bach et al., 2004). Treatment was applied at the cow level. Dry cows received the feed as top-dressing while head-locked for $30 \mathrm{~min}$ during the morning feeding to ensure that the treatment delivered was entirely consumed, and lactating cows received the treatments mixed in the TMR after obtaining permission to access specific feed bins containing the designated treatment.

At $14 \pm 2.6 \mathrm{~d}$ (average $\pm \mathrm{SD}$ ) before calving date, and exactly at 7 and $21 \mathrm{~d}$ after calving, and about $2 \mathrm{~h}$ from the morning delivery of feed, all cows were submitted to a rumen and a colon biopsy using an endoscope (CV-170 Optera, Olympus, Barcelona, Spain) equipped with a $1.68-\mathrm{m}$ probe (CF-Q165L, Olympus). Samples of rumen digesta were obtained by introduc- 
Table 1. Ingredient and nutrient composition of the rations for the dry and lactation periods

\begin{tabular}{lcc}
\hline Item & $\begin{array}{c}\text { Dry } \\
\text { period }\end{array}$ & $\begin{array}{c}\text { Lactation } \\
\text { period }\end{array}$ \\
\hline $\begin{array}{l}\text { Ingredient, \% of DM } \\
\text { Alfalfa hay }\end{array}$ & 5.83 & 4.96 \\
Rye grass hay & - & 9.29 \\
Fescue hay & 29.07 & 11.87 \\
Barley straw & 36.74 & 3.42 \\
Grass silage & - & 9.54 \\
Soybean meal & 14.22 & 8.04 \\
Canola meal & - & 2.17 \\
Corn grain & 4.15 & 26.99 \\
Barley grain & - & 8.91 \\
Wheat grain & 5.03 & - \\
Wheat middlings & - & 4.16 \\
Soybean hulls & - & 5.79 \\
Beet pulp & 4.31 & 3.58 \\
Calcium carbonate & 0.24 & 0.62 \\
Magnesium oxide & 0.24 & 0.17 \\
Sodium chloride & - & 0.33 \\
Mineral-vitamin premix ${ }^{1}$ & 0.16 & 0.17 \\
Nutrient, DM basis & & \\
CP, \% & 13.2 & 15.2 \\
NE , Mcal/kg & 1.31 & 1.62 \\
NDF, \% & 51.2 & 34.8 \\
Fat, \% & 1.67 & 2.58 \\
Ash, \% & 3.93 & 6.02 \\
NFC, \% & 30.0 & 41.4 \\
\hline Every kilogram of pro & & \\
\hline
\end{tabular}

${ }^{1}$ Every kilogram of premix contained $75 \mathrm{~g}$ of sodium sulfate, $30 \mathrm{~g}$ of zinc oxide, $5 \mathrm{~g}$ of copper sulfate, $15 \mathrm{~g}$ of manganese oxide, $1 \mathrm{~g}$ of potassium iodine, $0.5 \mathrm{~g}$ of cobalt acetate, $0.25 \mathrm{~g}$ of sodium selenite, 3,750 $\mathrm{kIU}$ of vitamin A, $750 \mathrm{kIU}$ of vitamin D, and $10 \mathrm{kIU}$ of vitamin $\mathrm{E}$

ing the endoscope probe protected with a transparent plastic sheath through the mouth [within a PVC tube of $2.5 \mathrm{~cm}$ internal diameter $(2.8 \mathrm{~cm}$ external diameter $)$ and $40 \mathrm{~cm}$ long that prevented the cow from chewing on the device] into the esophagus until reaching the dorsal part of the rumen liquid, then the plastic sheath was broken using biopsy forceps introduced through the biopsy canal of the endoscope, and a sample of digesta from the dorsal part of the rumen was collected through the endoscope. Samples of colon digesta were obtained about $135 \mathrm{~cm}$ from the anus using the same equipment (also covered with a transparent plastic sheath), but reaching the distal part of the colon via the rectum and using a caudal epidural anesthesia with $5 \mathrm{~mL}$ of lidocaine 2\% (Xylovet, Ceva, Libourne, France). Both rumen and colon samples, were snap frozen in liquid nitrogen and then kept frozen at $-20^{\circ} \mathrm{C}$ until subsequent DNA extraction. All the equipment was sterilized between samplings.

\section{Microbiota DNA Analysis and Bioinformatics}

The DNA from rumen and colon digesta was extracted and purified a commercial stool DNA isolation kit (Metabion, Steinkirchen, Germany) following the procedure suggested by the manufacture, and its pu- rity quantified by Nanodrop (Thermo Fisher Scientific, Waltham, MA). Then, DNA samples were quantified with a Qubit spectrophotometer to adjust concentrations at $20 \mathrm{ng} / \mu \mathrm{L}$. A volume of $20 \mu \mathrm{L}$ per sample was sent to a sequencing platform (W.M. Keck Center for Comparative and Functional Genomics at the University of Illinois at Urbana-Champaign). Diversity and composition of microbiota were determined using the high-throughput sequencing Illumina MiSeq (Illumina, San Diego, CA) method $(2 \times 250$ nt paired ends $)$. To construct the $16 \mathrm{~S}$ amplicon libraries, the V3-V4 hypervariable region of the bacterial $16 \mathrm{~S}$ rDNA was characterized using V3_F357_N and V4_R805 primers (Klindworth et al., 2013). Samples were diluted to 2 $\mathrm{ng} / \mu \mathrm{L}$ concentrations. A mastermix for amplification was prepared using the Roche High Fidelity Fast Start Kit and 20× Access (Roche Applied Science, Penzberg, Germany). Then, $1 \mu \mathrm{L}$ of DNA sample and $1 \mu \mathrm{L}$ of Fluidigm Illumina linkers with unique barcodes were added. Array loading reagent according to Fluidigm protocols. All samples were run on a fragment analyzer (Advanced Analytics, Ames, IA) and amplicon regions and expected sizes were confirmed. Samples were then pooled in equal amounts according to product concentration. The pooled products were then size-selected on a 2\% agarose E-gel (Life Technologies) and extracted from the isolated gel slice with Qiagen gel extraction kit (Qiagen Ltd., West Sussex, UK) using a Qiacube robot. Cleaned size-selected products were run on an Agilent Bioanalyzer (Agilent Technologies, Santa Clara, CA) to confirm appropriate profile and determination of average size.

Quality score ASCII offset was established to 33. A bioinformatics pipeline based on mothur (Schloss et al., 2009) was used for sequence processing and classification. The 16S rRNA SILVA database (release 312; Quast et al., 2013) was used as a reference. A first trimming step was conducted using Trimmomatic (version 0.36; Bolger et al., 2014), discarding sequences below $220 \mathrm{bp}$ in length and with an average quality score below 30 on a window of 20 bases. After trimming, a total of 2,060,469 reads were processed, aligned, and then reads larger than 500 bases, duplicated, and those with one or more ambiguous positions were discarded. The paired $R 1$ and $R 2$ reads were joint. Sequence alignment was made using the mothur-recreated SILVA seed database, followed by a preclustering process grouping reads with less than 2-nucleotide difference together. Chimera filtering was performed using UCHIME (version 4.2.40; Edgar et al., 2011) versus the SILVA-based alignment of template file for chimera removal (https:/ /mothur.org/wiki/Silva_reference_files\#Release_132). The distance between the remaining DNA sequences was calculated using the dist.seqs() option in mothur, 
followed by the cluster() command to assign sequences into operational taxonomic units (OTU) using the opticlust algorithm (Westcott and Schloss, 2017). The Wang approach (Wang et al., 2007) was chosen as the taxonomy classification method using a kmer size of 8 nt and the NR SILVA database as reference. Chloroplast and mitochondrial lineages were removed. A total of 1,494,097 reads were kept for taxonomy classification. Mothur output was processed in $\mathrm{R}$ (version 3.5.1; $\mathrm{R}$ Core Team, 2018). Data were structured in a phyloseq object using the phyloseq package (version 1.24.2; McMurdie and Holmes, 2013), adding factor metadata and then transformed to relative abundances, filtered using detection and prevalence limits of 10 and 5\%, respectively, and normalized.

\section{Calculations and Statistical Analysis}

Beta diversity across all samples was calculated using the Bray-Curtis dissimilarity, and a gradient analysis for each site (rumen or colon) was performed using nonmetric multidimensional scaling. Genus-level Shannon diversity index was calculated as $-\Sigma P_{i} \ln \left(P_{i}\right)$ where $P_{i}$ is the proportion of individuals belonging to the genus $i$. The phyloseq (version 1.24.2; McMurdie and Holmes, 2013) function estimate_richness() was used for this purpose. Feed efficiency was calculated as milk yield divided by DMI.

The potential effect of time relative to calving, dietary treatment, and their interaction on relative abundance of microorganisms in both the rumen and colon was assessed using a multivariate ANOVA with the Limma package (version 3.36.5; Ritchie et al., 2015) for R (version 3.5.1; R Core Team, 2018) correcting for false discovery rate following Benjamini and Hochberg (1995). The false discovery rate-adjusted $P$-values are shown throughout the manuscript.

Also, average DMI, milk yield, and feed efficiency on $\mathrm{d} 4,5,6,7,8,9$, and 10 and average DMI, milk yield, and feed efficiency on d 18, 19,20,21,22, 23, and $24 \mathrm{~d}$ after calving were calculated, and the correlation between these traits and the relative abundances of genera in the rumen and colon at d 7 and 21 after calving, respectively, were determined. Similarly, DMI after calving was averaged over the first 21 DIM, and the correlations between DMI after calving and the relative abundance of genera in the rumen and colon at $14 \mathrm{~d}$ before calving were determined.

\section{RESULTS AND DISCUSSION}

Milking performance, DMI, and feed efficiency of the cows in this study are reported elsewhere (Bach et al., 2018). In brief, DMI during the first 21 DIM was greater $(P<0.05)$ in LY $(18.2 \pm 0.77 \mathrm{~kg} / \mathrm{d})$ than in control cows $(15.7 \pm 0.77 \mathrm{~kg} / \mathrm{d})$. Milk yield was also greater $(P<0.05)$ in LY $(38.7 \pm 2.85 \mathrm{~kg} / \mathrm{d})$ than in control cows $(32.7 \pm 2.85 \mathrm{~kg} / \mathrm{d})$.

In the current study, we focused on taxonomic classification at the genus, not OTU, level to assess changes in the microbiome. Focusing on the genus facilitates comparisons with other studies and making inferences about functionality of the microbiota. Several studies have shown that using 16S rRNA and current existing databases, such as SILVA, rumen communities can be reasonably well represented at the genus level (Fouts et al., 2012; Větrovský and Baldrian, 2013).

\section{Microbial Diversity}

The number of OTU, evenness, and richness from rumen and colon samples obtained at each sampling point are shown in Table 2. A gradient analysis of the $\beta$-diversities in the rumen and in the colon is plotted in Figure 1. Rumen samples (Figure 1A) could be more closely grouped across physiological stages than those from the colon (Figure 1B), indicating that microbial diversity across individuals was less affected by diet in the colon than in the rumen. Shannon measurements of $\alpha$ diversity were affected $(P<0.05)$ by time of sampling relative to calving in both locations, rumen and hindgut. Genus-level Shannon diversity index in the rumen was lowest at $7 \mathrm{~d}$ after calving (Figure 2), and the greatest $(P<0.05)$ Shannon index in the colon (Figure 3) was observed precalving $(-14 \mathrm{~d})$; however, no differences were found between control and LY cows and there was no interaction between treatment and time relative to calving. Nevertheless, LY cows showed slightly and nonsignificant greater microbial diversity (measured as Shannon $\alpha$ diversity) than control cows in the colon at all sampling times (Figure 4). An increased diversity index indicates that there are few predominant genera among all possible observations. Thus, at $14 \mathrm{~d}$ before calving, microbial biodiversity in the rumen of dairy cows was greatest, and it decreased at $7 \mathrm{~d}$ after calving (most likely due to the drastic change in diet composition and DMI), but at $21 \mathrm{~d}$ after calving, cows showed the same genus-level Shannon diversity than they had before calving. Contrarily, in the colon, microbial diversity decreased after calving and remained lower at 7 and $21 \mathrm{~d}$ after parturition compared with the values before calving (Figure 3). One possible explanation for the reduced biodiversity in the colon after calving could be the lower content of dietary fiber and greater digestibility of the lactation ration, which would lead to a lower availability of substrate to sustain growth of some bacteria in the hindgut, because a larger proportion of nutrients would have been absorbed in previous 
Table 2. Number of operational taxonomic units (OTU), evenness, and richness from rumen and colon samples obtained at d $-14,7$, and 21 relative to calving

\begin{tabular}{|c|c|c|c|c|c|c|c|}
\hline Tissue & Time, $\mathrm{d}$ & \multicolumn{2}{|c|}{ OTU } & \multicolumn{2}{|c|}{ Evenness $(\text { Evar })^{1}$} & \multicolumn{2}{|c|}{ Richness $(\text { Chao } 1)^{2}$} \\
\hline Rumen & 21 & 5,673 & $1,179.9$ & 0.811 & 0.0180 & 43,562 & $9,239.4$ \\
\hline \multirow[t]{2}{*}{ Intestine } & -14 & 6,440 & $2,235.5$ & 0.866 & 0.0199 & 68,791 & $22,668.4$ \\
\hline & 7 & 5,908 & $1,921.9$ & 0.836 & 0.0317 & 57,670 & $21,661.9$ \\
\hline
\end{tabular}

${ }^{1}$ Evar $=$ Smith and Wilson's Evar index following Smith and Wilson (1996).

${ }^{2} \mathrm{Chao} 1=$ richness index following Chao (1984).

segments of the gastrointestinal tract. Interestingly, the Shannon diversity was slightly greater in the colon than in the rumen, an observation that has also been reported in sheep (Perea et al., 2017).

\section{Rumen Microbiota}

There was an interaction $(P<0.05)$ between treatment and time relative to calving for relative abundances of Flexilinea, Bacteroidales (group UCG-001), Lachnospiraceae (groups UCG-002 and UCG-006), and Streptococcus (Figure 5). Most of the effects of LY supplementation on rumen microbiota were observed before calving (i.e., just $1 \mathrm{wk}$ after LY supplementation), when the relative abundances of Bacteroidales (group UCG-001), Lachnospiracea (groups UCG-002 and UCG-006), and Flexilinea increased with LY supplementation (Figure 5). However, the relative abundance of Streptococcus was greater in LY than in control cows on d 21 after calving (Figure 5). Flexilinea is a filamentous strictly anaerobic gram-negative bacterium that has been reported to require yeast substrates to grow (Sun et al., 2016). Flexilinea ferments all kinds of carbohydrates and its growth is enhanced in the presence of methanogens (Sun et al., 2016). Bacteroidales has been reported to be more abundant in high-forage than in low-forage diets and it has been associated with fiber digestion (Henderson et al., 2015) and biohydrogenation of fatty acids in the rumen (Castro-Carrera et al., 2014). Members of the Lachnospiraceae family are gram-positive anaerobic rod-shaped bacteria that mainly ferment pectin (Cotta and Forster, 2016) and are present in the rumen of lactating cows in relative low proportions (Jiang et al., 2017b). Contrary to the results herein, Jiang et al. (2017b) reported that lactating dairy cows at the end of their lactation supplemented with live Saccharomyces cerevisiae experienced a decrease in relative abundances of Lachnospiraceae, whereas in the current study Saccharomyces cerevisiae supplementation resulted in an increase in relative abundances of Lachnospiraceae before calving and had

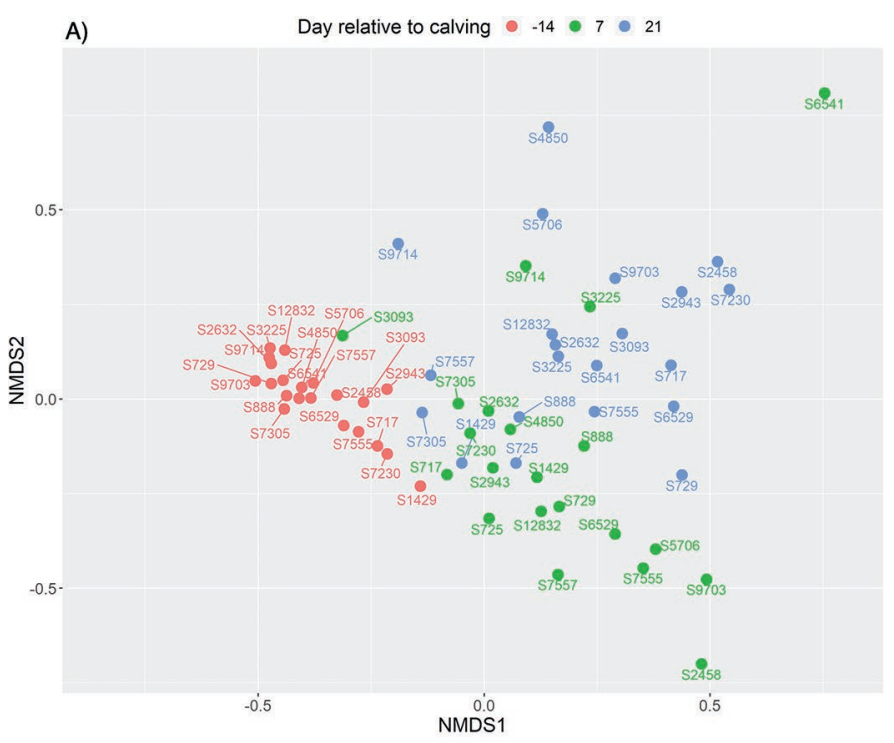

B)

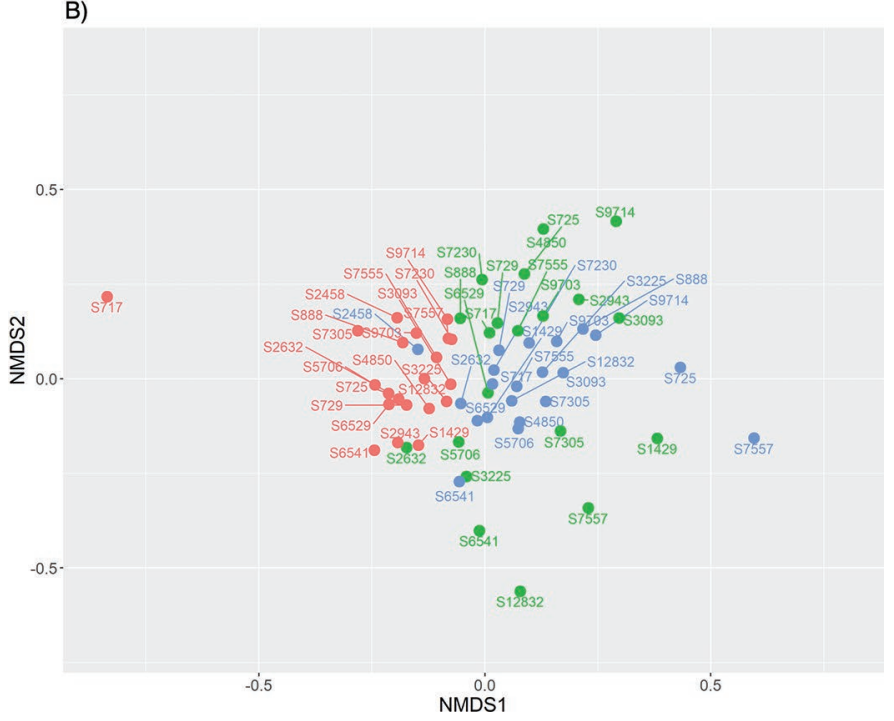

Figure 1. Nonmetric multidimensional scaling (NMDS) of $\beta$-diversity index (using Bray-Curtis distances) of all rumen (A) and colon (B) samples. 
no influence after calving. Differences in responses to Saccharomyces cerevisiae could be due to the type of ration fed to cows, the productive stage (early vs late lactation), or the strain that was supplemented, which was different in Jiang et al. (2017a) than in the current study. Last, Streptococcus, which increased in LY cows at $21 \mathrm{~d}$ after calving, is a genus that includes several gram-positive and homofermentative species, among them Streptococcus bovis, commonly associated with production of lactic acid from starch fermentation in the rumen (Dehority, 2003). Thus, LY supplementation was able to maintain the number of Streptococcus relatively low at $7 \mathrm{~d}$ after calving but not at $21 \mathrm{~d}$. However, this difference could be due to the amount of starch and other carbohydrate sources that entered the rumen, which were considerably greater in LY than in control cows, as the latter consumed $2.5 \mathrm{~kg} / \mathrm{d}$ less $(P$ $<0.05)$ DM after calving than LY cows (Bach et al., 2018).

Overall, changes in the ruminal microbial community were more drastic across days relative to calving than as influenced by the dietary treatment (control or LY). Changes in the microbial community of the rumen across sampling times and dietary treatments are depicted in Figure 6. Table 3 lists the genera whose relative abundance in the rumen decreased after calving, whereas Table 4 depicts those genera with an increased relative abundance in the rumen after calving, independent of dietary treatment.
The genera Christensenellaceae (group c) and Christensenellaceae (group R-7) were highly abundant $(>30 \%)$ in the rumen before calving but markedly decreased after calving (Table 3). Lima et al. (2015) already described large changes in the relative abundances of this family in the rumen around calving. The family Christensenellaceae has been associated with fermentation of structural carbohydrates producing mainly acetic and butyric acid as main end products (Morotomi et al., 2012), and in mice it has been associated with reduced adiposity (Goodrich et al., 2014). Similarly, Rikenellaceae (group RC9) was also highly abundant $(\sim 10 \%)$ before calving and decreased thereafter. Zened et al. (2013) reported similar relative abundances of Rikenellaceae (group RC9) in the rumen of cows consuming low-starch diets (similar to the one fed during the dry period herein) and they also reported that the relative abundance of Rikenellaceae (group RC9) in the rumen decreased as the starch content of the ration increased. Thus, the results herein are consistent with dietary changes that cows experienced when transitioning from a dry to a lactating ration.

Fourteen days before calving, the relative abundance of several genera of Ruminococcaceae (Ruminococcaceae groups UCG-010, UCG-013, NK4A214, UCG-005, UCG-002, and unclassified) in the rumen added up to $7.6 \%$, and it decreased $(P<0.05)$ to $4.2 \%$ after calving (Table 3), which are values similar to those reported by Jiang et al. (2017b) in late lactation cows. Some

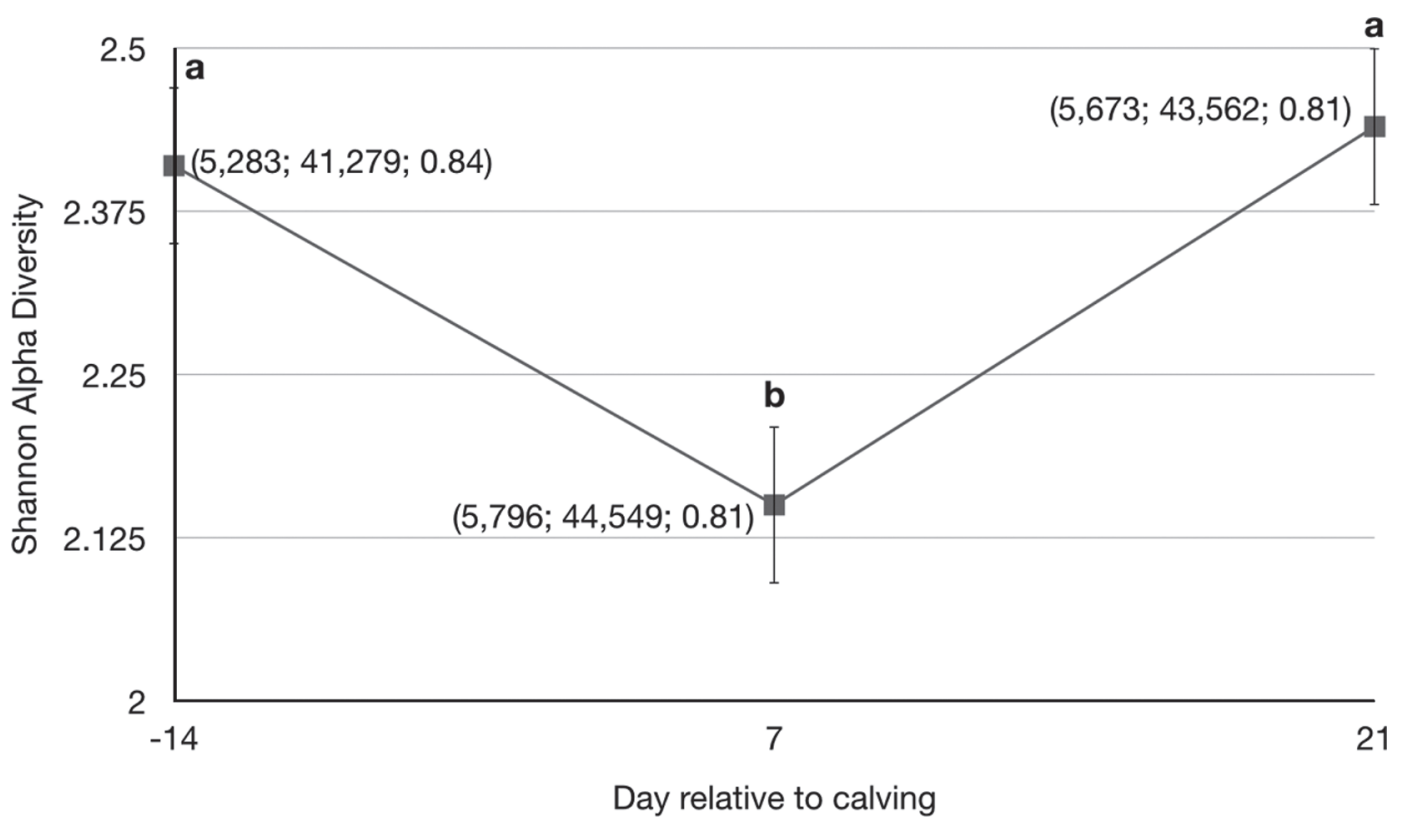

Figure 2. Shannon diversity index in the rumen as affected by time relative to calving in dairy cows. Values across time with uncommon letters $(\mathrm{a}, \mathrm{b})$ differ at $P<0.05$. Values within parentheses for each sampling point represent the average number of operational taxonomic units, the average Chao1 richness index (Chao, 1984), and average Smith and Wilson's Evar index (Smith and Wilson, 1996) of evenness (distribution of individuals over genera), respectively. Error bars depict SE. 


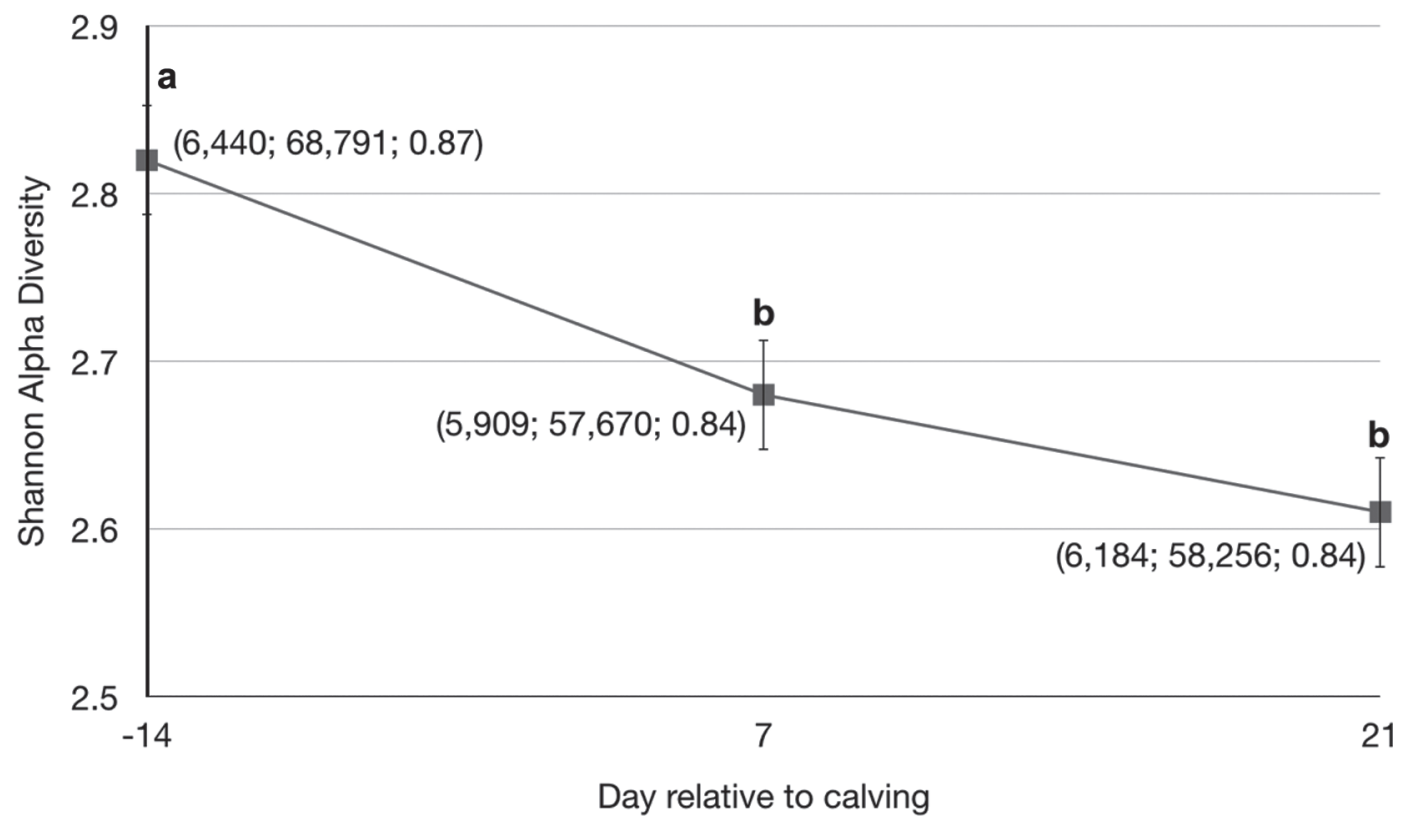

Figure 3. Shannon diversity index in the colon as affected by time relative to calving in dairy cows. Values across time with uncommon letters $(\mathrm{a}, \mathrm{b})$ differ at $P<0.05$. Values within parentheses for each sampling point represent the average number of operational taxonomic units, the average Chao1 richness index (Chao, 1984), and average Smith and Wilson's Evar index (Smith and Wilson, 1996) of evenness (distribution of individuals over genera), respectively. Error bars depict SE.

members of the Ruminococcaceae family, such as the well described Ruminococcus albus and R. flavefaciens, are known to participate in fiber digestion (Forsberg and White, 1997), and thus it would be reasonable to expect greater number of these bacteria during the dry period than during the lactation period, as observed

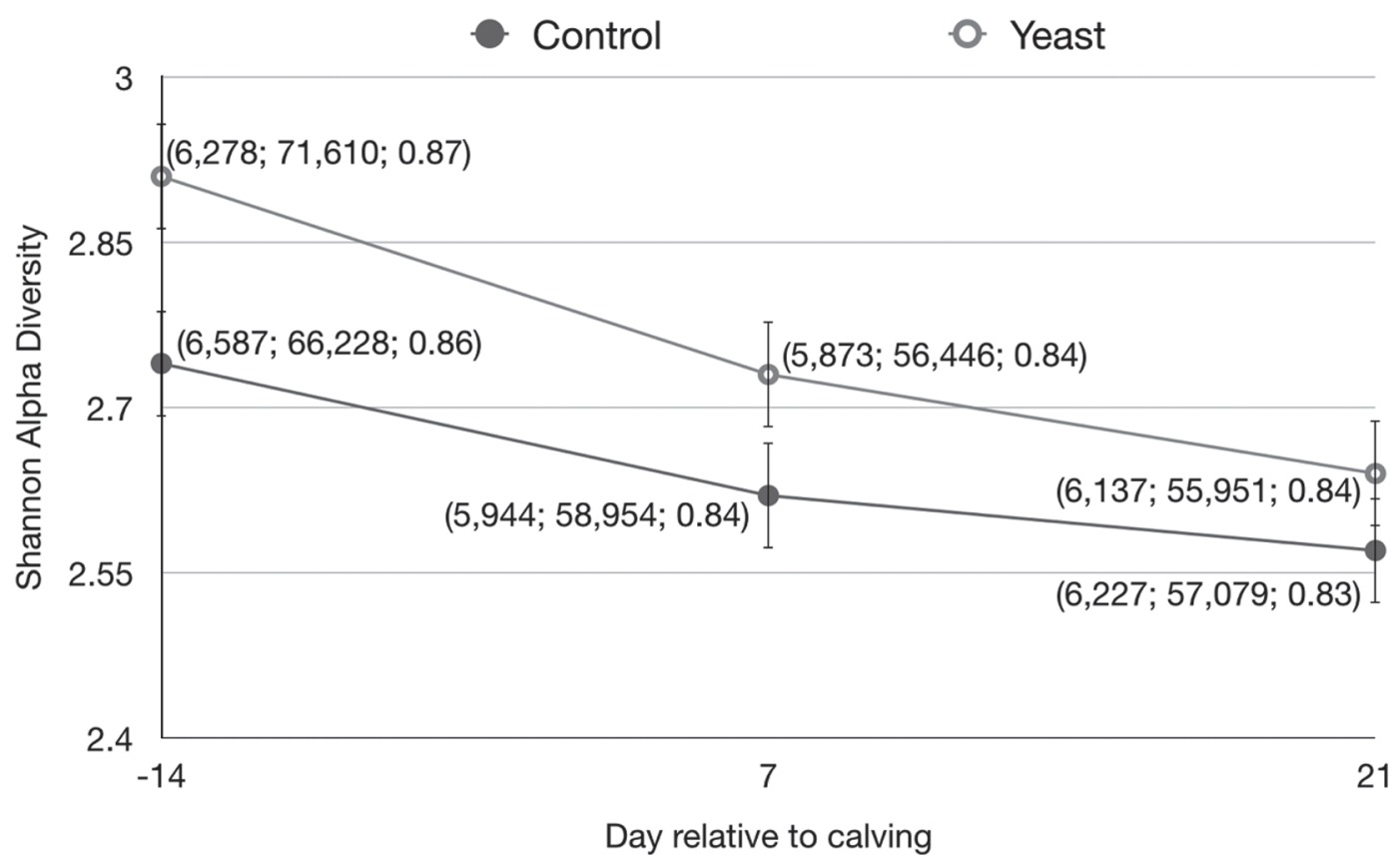

Figure 4. Shannon diversity index in the colon as affected by dietary yeast supplementation and time relative to calving in dairy cows. Values within parentheses for each sampling point represent the average number of operational taxonomic units, the average Chao1 richness index (Chao, 1984), and average Smith and Wilson's Evar index (Smith and Wilson, 1996) of evenness (distribution of individuals over genera), respectively. Error bars depict SE. 
herein. However, the relative abundance of some other Ruminococcaceae genera increased after calving following different patterns (Table 4). Ruminococcus groups 2 and c experienced a 2 -fold increase in relative abundance $7 \mathrm{~d}$ after calving and then returned to similar values as precalving (Table 4), whereas Ruminococcaceae group UCG-014 progressively increased from $0.5 \% 14 \mathrm{~d}$ before calving to $1.7 \% 21 \mathrm{~d}$ after calving (Table 4). It is interesting to note the 2 different patterns among the 4 most abundant genera within the Ruminococcaceae family, 2 taxa (groups NK4A214 and unclassified) were negatively affected by transition with a sharp decrease followed by a maintenance of low levels postcalving, whereas the other 2 (groups 2 and c) showed a transient increase by more than 2 -fold 1 wk postcalving and returned to precalving values thereafter. This result supports, again, the high functional diversity reported within the Ruminococcaceae family (which also includes bacteria that ferment starch) and the difficulty to infer functions based on amplicon sequencing data.
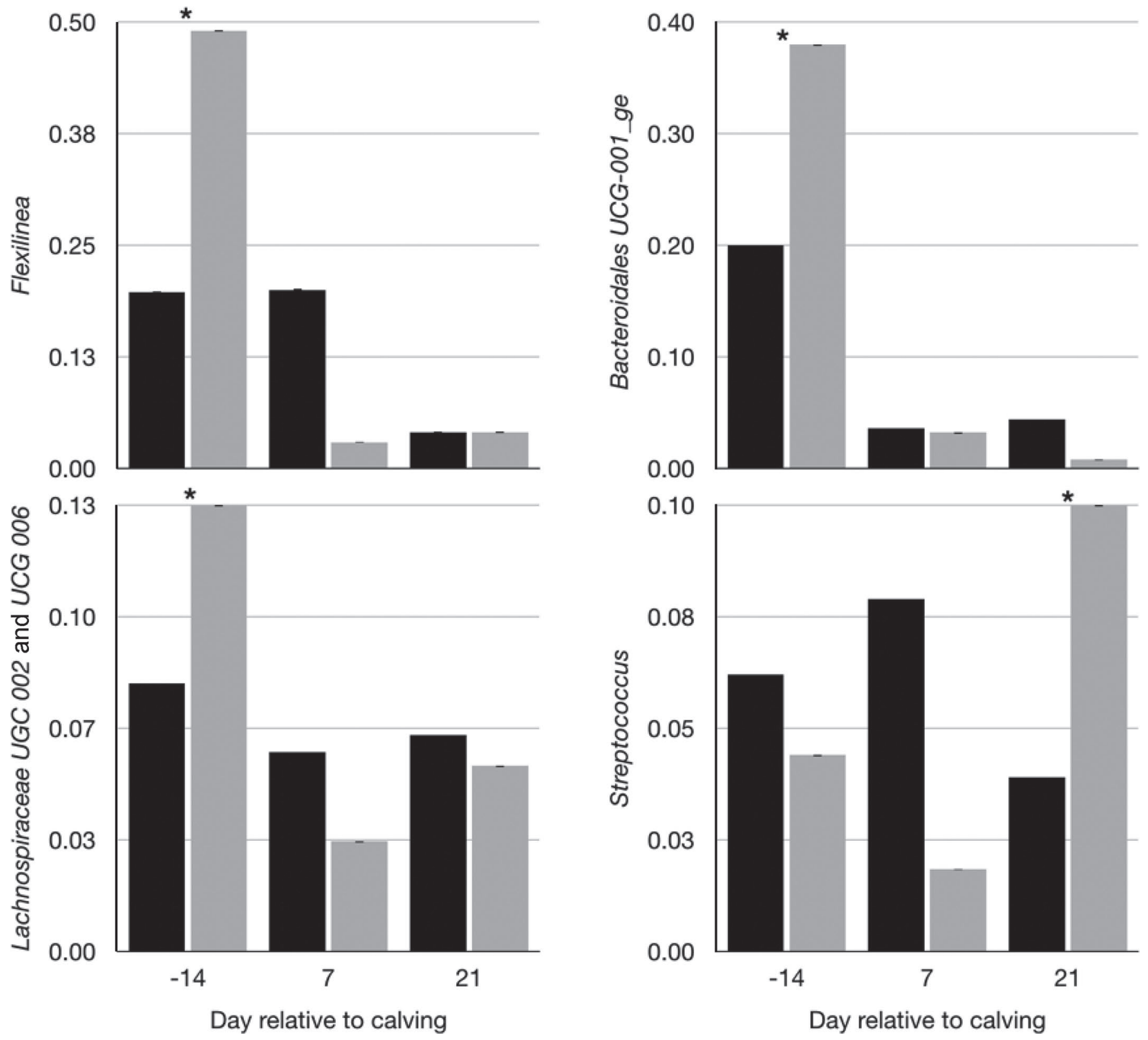

Figure 5. Ruminal relative abundance $(\%)$ of the genera detected in the rumen as affected by days around calving and dietary treatment. Black bars depict control cows and gray bars represent cows on the live yeast treatment. Asterisks denote differences $(P<0.05)$ between dietary treatments within day relative to calving. Error bars denote SE. 
Clostridiales (unclassified) represented $6.3 \%$ of the relative abundance of total prokaryotes in the rumen $14 \mathrm{~d}$ before calving, and then decreased to $4.9 \%$ after calving (Table 3). Lima et al. (2015) also reported Clostridiales as an abundant taxon before calving in dairy cattle. Last, a small number of archaeal sequences were identified as previously reported in recent studies using similar primers (Yeoman et al., 2018). The relative abundance of Methanobrevibacter in the rumen (Figure 6$)$ decreased $(P<0.05)$ by half, from a relative abundance of $5.9 \%$ at $14 \mathrm{~d}$ before calving to $2.9 \%$ after calving (Table 3). Methanobrevibacter is the most abundant genus of methane producers in the rumen (Zhou et al., 2009). It is well established that a highforage ration, such as those fed during the dry period, typically results in greater methane production in the rumen than high-grain rations (Aguerre et al., 2011).

Conversely, the relative abundance of some Prevotella (groups c, 1, 7, YAB2003, UCG-004, and unclassified), Lachnospiraceae (groups c, NK3A20, and unclassified), Muribaculaceae (unclassified), Acetitomaculum (pertaining to the Lachnospiraceae family), and Olsenella genera, among others, sharply increased after calving (Table 4). Different genera of Prevotellaceae (groups

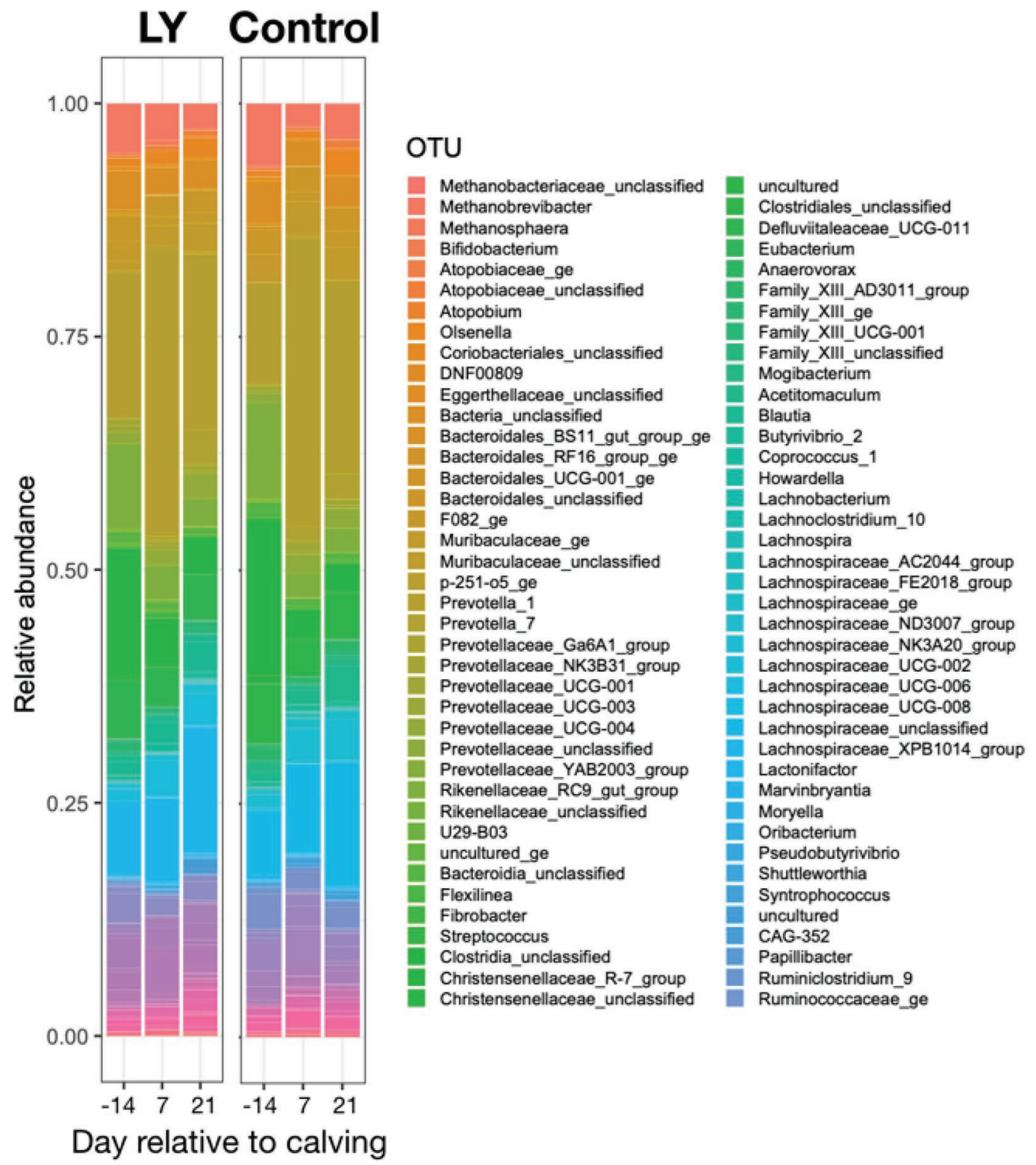

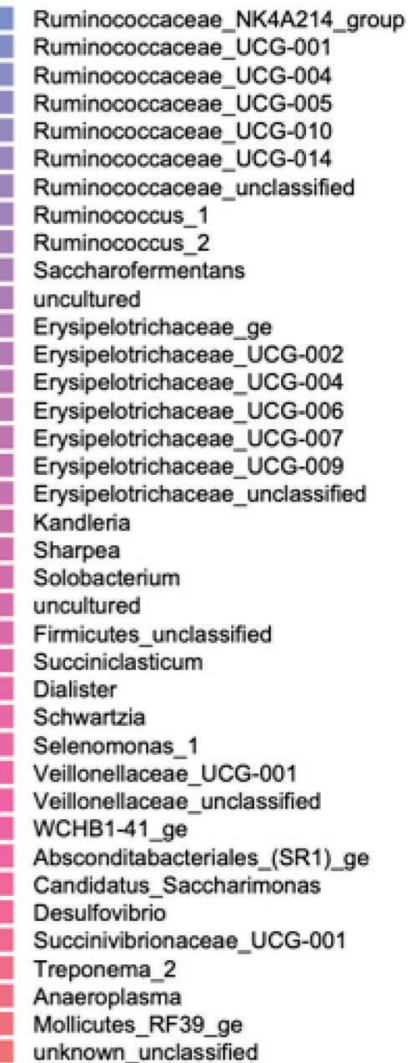

unknown_unclassified

Figure 6. Relative abundance of the genera detected in the rumen of dairy cattle as influenced by live yeast (LY) supplementation and time relative to calving. OTU $=$ operational taxonomic units. 
c, 1, 7, YAB2003, UCG-004, and unclassified) together represented $27.6 \%$ of prokaryotes in the rumen of dry cows, but after calving all these genera increased by several orders of magnitude. At $7 \mathrm{~d}$ after calving, some Prevotella genera (groups c, 1, and YAB2003) increased by 2 - and 20 -fold in relative abundance during the dry period and then decreased to levels that were still much greater than those found in the dry period (Table 4). On the other hand, the relative abundance of other Prevotella genera (groups UCG-004, 7, and unclassified) progressively increased linearly as lactation progressed (Table 4). The genus Prevotella is generally found with high abundance in the rumen and has many key roles such as polysaccharide and protein breakdown as well as sugar fermentation (Deusch et al., 2017). Classical studies have shown that Prevotella exhibits substantial metabolic diversity as it is present in the rumen across a variety of diets (Stevenson and Weimer, 2007), and it has also been shown to be able to grow effectively at $\mathrm{pH}$ as low as 5.1 (Russell and Dombrowski, 1980). In a former study, Prevotella exhibited the greatest change between clinical and subclinical acidotic heifers with more than a $26 \%$ increase $4 \mathrm{~h}$ after an acidotic challenge (Petri et al., 2013). It could be speculated that the increased relative abundance herein would be an indication that after calving, rumen $\mathrm{pH}$ might have decreased, as reported elsewhere (Humer et al., 2015), and this rumen environment could offer a competitive advantage to species of this genus. However, the relative abundance of Prevotella was not affected $(P=0.13)$ by the interaction between dietary treatment and time relative to calving (with the relative abundance of Prevotella being numerically lower in LY than in control cows), which would indicate that rumen $\mathrm{pH}$ between control and LY cows probably did not substantially differ after calving. However, several studies have reported improvements in rumen $\mathrm{pH}$ when supplementing lactating cows with LY (Bach et al., 2007; Thrune et al., 2009; DeVries and Chevaux, 2014). The hypothetical lack of differences in rumen $\mathrm{pH}$ (as potentially indicated that the relative abundance of Prevotella) could be found in the important differences in DMI, which was much greater in LY than in control cows. Because LY cows consumed more feed, a lower rumen $\mathrm{pH}$, and

Table 3. Genera whose relative abundance (\%) in the rumen decreased after calving

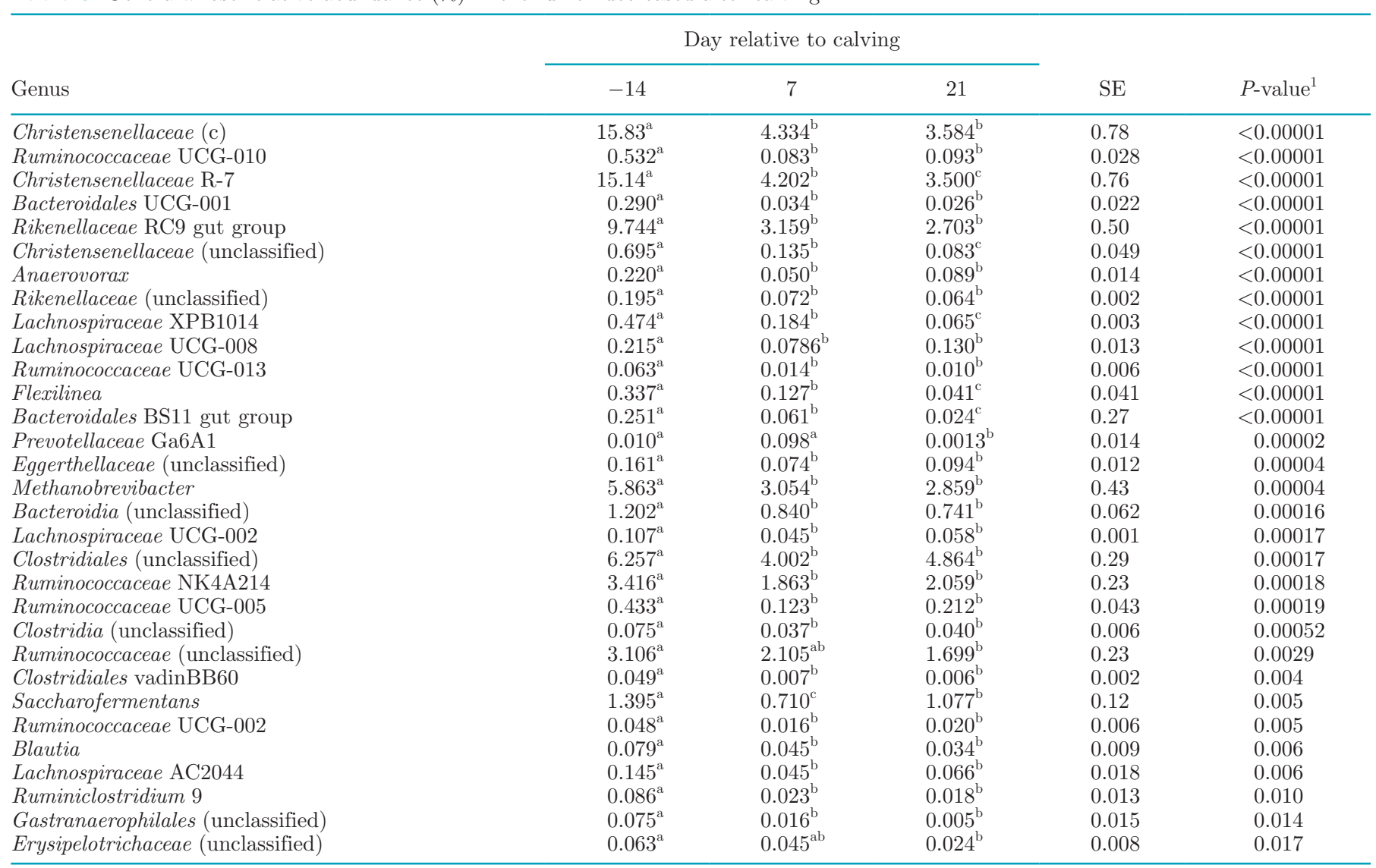

${ }^{\bar{a}-c}$ Values with uncommon superscripts within genus differ at $P<0.05$.

${ }^{1}$ Effect of time relative to calving. 
greater relative abundances of Prevotella would have been expected unless LY had exerted an effect on rumen $\mathrm{pH}$.

Within the family of Lachnospiraceae, some genera, particularly predominant ones (groups c, NK3A30, and unclassified) increased in relative abundance after calving (Table 4), whereas some minor genera (groups AC2044, UGC-002, UCG-008, and UCG-013) lost relative abundance (Table 3). Zhu et al. (2018) reported an increase in the relative abundance of the family Lachnospiraceae, but Pitta et al. (2014) reported a decreased relative abundance of this family as cows transitioned from a dry to a lactation ration. Differences at the family level between these 2 studies could most likely be explained by the different behavior observed herein of the genera within this taxon, with some genera increasing and others decreasing when transitioning from a dry to a lactating ration. As stated above Lachnospiraceae has been implicated in pectin fermentation, but little is known about the role of this family in the rumen.

\section{Colon Microbiota}

Overall, the effect of LY in the colon was much more moderate than in the rumen (Figure 7 ). The relative abundance of Alloprevotella, Bacteroides, and Phascolarctobacterium in the colon were lower $(P<0.05)$ in LY $(0.07 \pm 0.02,0.76 \pm 0.25$, and $0.022 \pm 0.009 \%$, respectively) than in control $(0.18 \pm 0.02,3.75 \pm 0.26$, and $0.06 \pm 0.009 \%$, respectively) cows, independent of time of sampling. Contrarily, the relative abundance of Eggerthellaceae (unclassified) in the colon was greater $(P<0.01)$ in $\mathrm{LY}(0.20 \pm 0.018 \%)$ than in control $(0.13$ $\pm 0.018 \%)$ cows, independent of time of sampling. Eggerthellaceae has been linked to the degradation of polycyclic (i.e., polyphenols) compounds (Clavel et al., 2006; Selma et al., 2014), with corresponding health benefits, and metabolism of bile acids (Harris et al., 2018), modulating the physicochemical properties of bile acids (Devlin and Fischbach, 2015) and thus allowing downstream metabolism and utilization by other intestinal microbes.

Table 4. Genera whose relative abundance (\%) in the rumen increased after calving

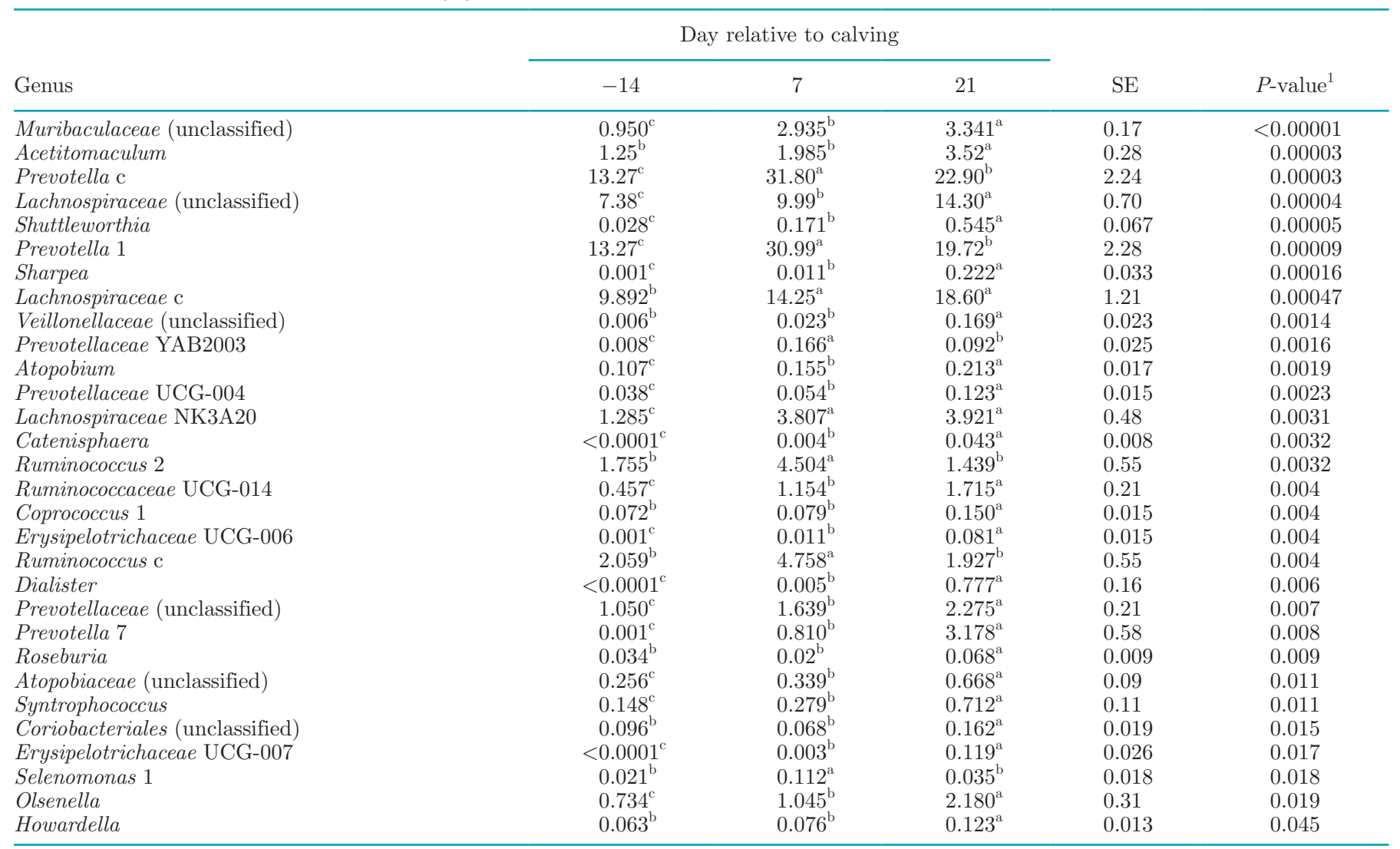

${ }^{\mathrm{a}-\mathrm{c}}$ Values with uncommon superscripts within genus differ at $P<0.05$.

${ }^{1}$ Effect of time relative to calving. 
The relative abundance of Ruminiclostridium group 5 in the colon was affected by an interaction $(P<0.05)$ between dietary treatment and time, mainly due to a greater $(P<0.05)$ relative abundance of Ruminiclostridium group 5 in control $(0.07 \pm 0.01 \%)$ than in LY $(0.04 \pm 0.01 \%)$ cows before calving with no differences in relative abundance $(0.03 \pm 0.01 \%)$ after calving between the 2 dietary treatments. The relative abundance of the other detected genera in the colon was unaffected by dietary treatment or its interaction with time.

Marked changes were observed in relative abundances of several genera in the colon across time. Table 5 shows the genera whose relative abundance decreased after calving in relation to precalving. Christensenellaceae (group c), Christensenellaceae (group R-7), Clostridiales (unclassified), and Rikenellaceae (group RC9) gut groups were among the most abundant $(>30 \%)$ genera in the colon before calving and experienced a marked decrease after calving. Members of the Christensenellaceae family are typically butyrate producers (Morotomi et al., 2012) and have been commonly associated with intestinal health and decreased inflammation (Goodrich et al., 2014; Jenkins et al., 2015; Tigchelaar et al., 2016). Similarly, the abundance of Clostridiales has been linked with a reduced inflammation due to increased expression of IL-10 in the colon (Atarashi et

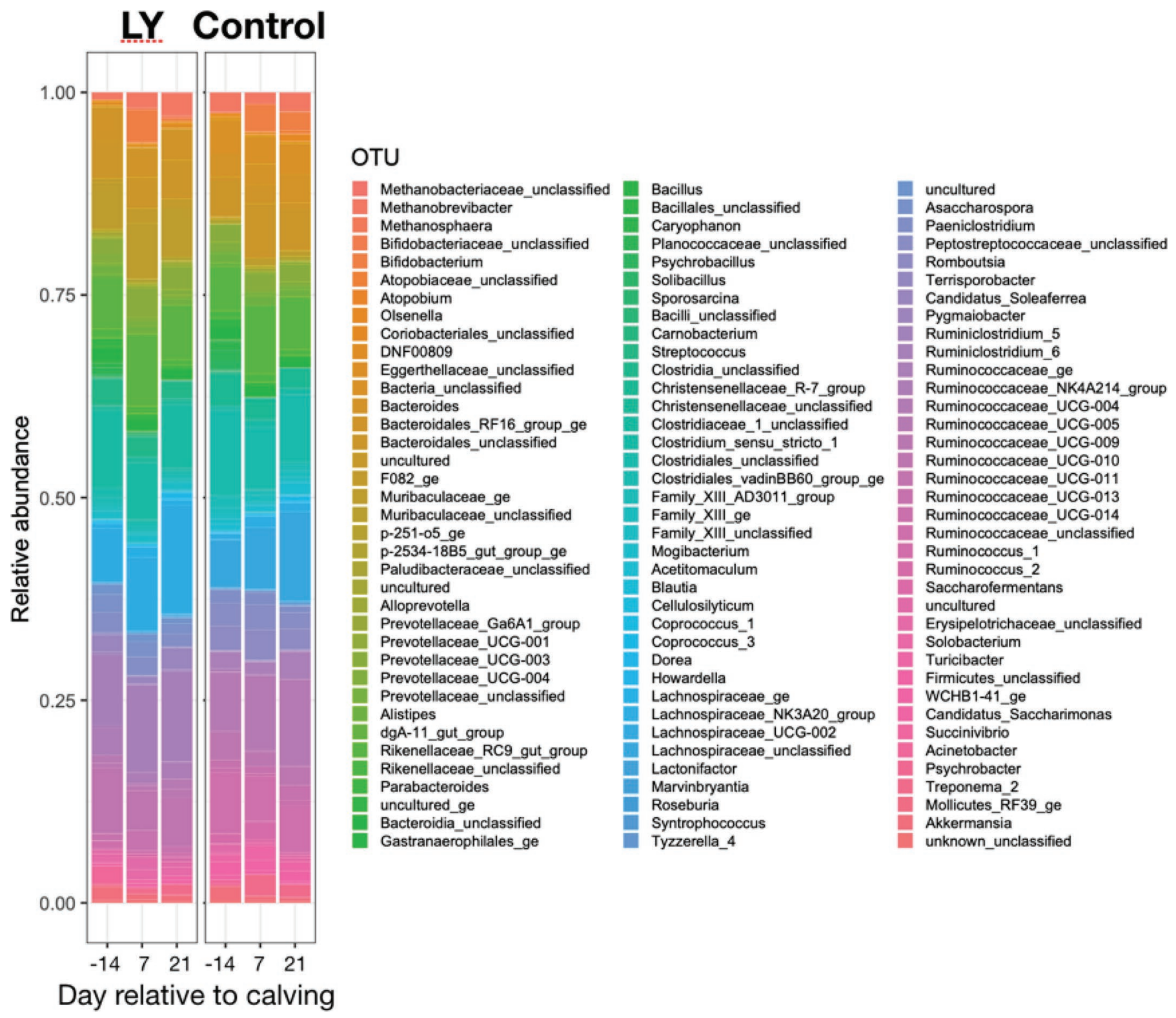

Figure 7. Relative abundance of the genera detected in the colon of dairy cattle influenced by live yeast (LY) supplementation and time relative to calving. OTU $=$ operational taxonomic units. 
Table 5. Genera whose relative abundance (\%) in the colon decreased after calving

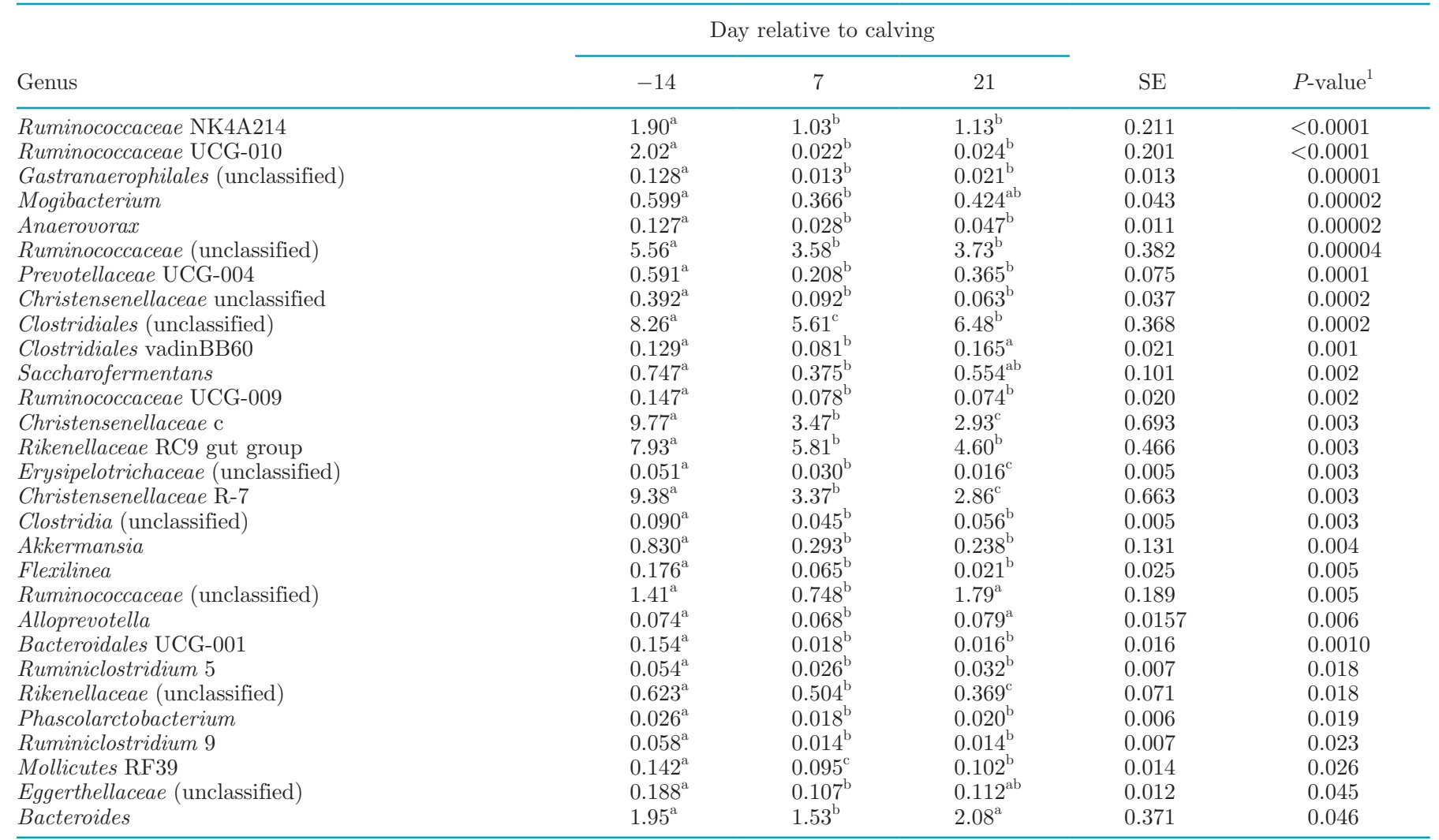

${ }^{a-c}$ Values with uncommon superscripts within genus differ at $P<0.05$.

${ }^{1}$ Effect of time relative to calving.

Table 6. Genera whose relative abundance (\%) in the colon increased after calving

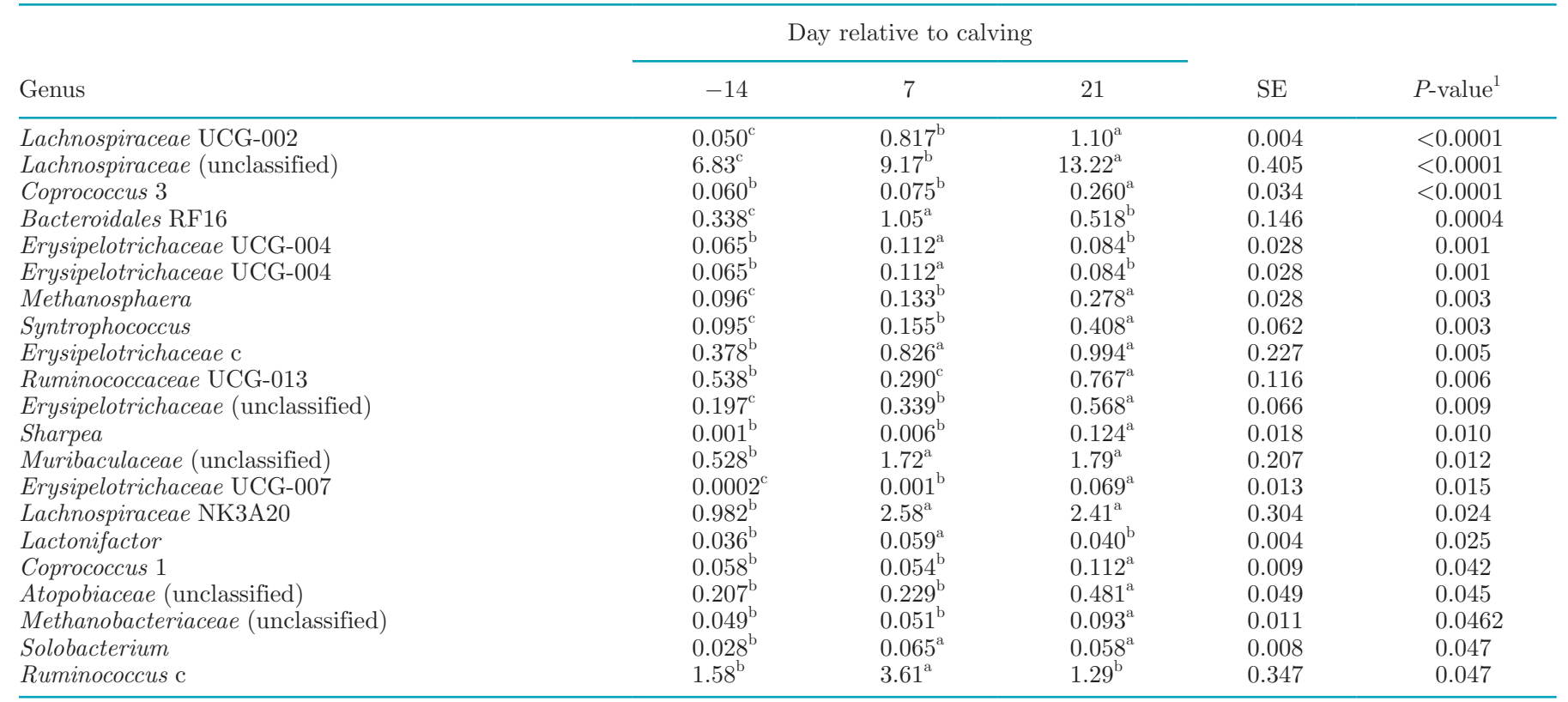

${ }^{\mathrm{a}-\mathrm{C}}$ Values with uncommon superscripts within genus differ at $P<0.05$.

${ }^{1}$ Effect of time relative to calving. 
al., 2011). However, the expression of IL-10 and other interleukins in the colon of the cows used herein (data reported in Bach et al., 2018) was not affected by time relative to calving; thus, the decrease in relative abundance of Christensenellaceae herein did not seem to be sufficiently large to induce any change in the transcriptomic response of selected genes associated with inflammation status of the colon throughout transition. Last, genera within the family Rikenellaceae produce acetate, succinate, and propionate as main fermenta- tion products within the large intestine of cattle (Kong et al., 2010; Jeong et al., 2011; Abe et al., 2012), and their abundance has been associated with high-forage diets (Petri et al., 2013) as it was the case in this study for the dry-cow ration.

On the contrary, the relative abundance of Lachnospiraceae (unclassified) and Lachnospiraceae (group NK3A20) in the colon increased by about 2-fold after calving compared with precalving values (Table 6). Lachnospiraceae is a major butyrate-producing

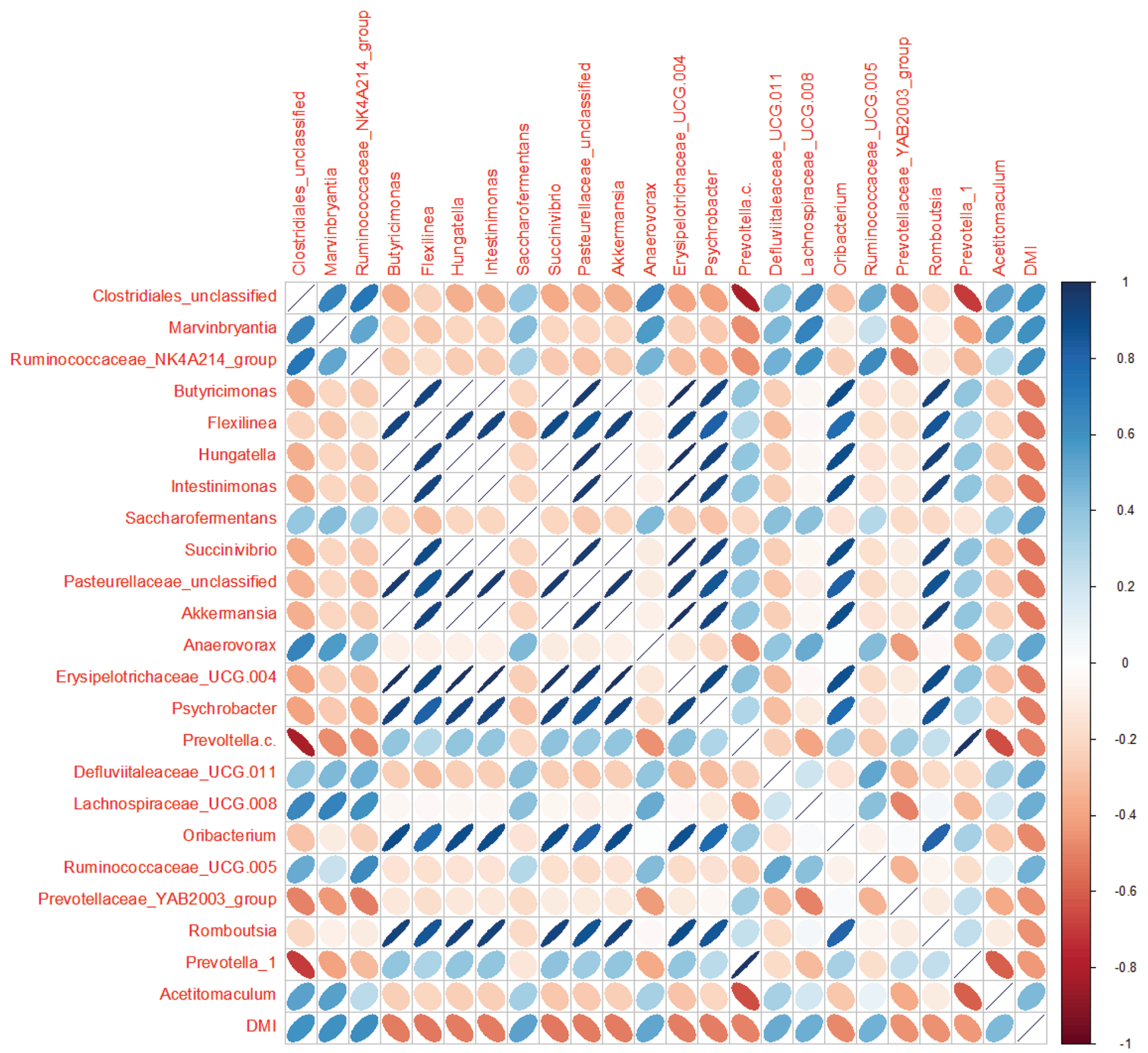

Figure 8. Correlation of ruminal genera that were significantly $(P<0.05)$ associated with DMI after calving. 
Firmicutes, but little is known about their activity in the colon of ruminants. All the other genera showing an increase in relative abundances after calving in the colon were minor genera (relative abundances $<0.6 \%$ ). The relative abundance of Coprococcus (both groups 1 and 3) markedly increased after calving (Table 6), which could be expected, as Coprococcus is a butyrate producer that has been associated with the feeding of high-grain diets (Kim et al., 2014).
Several genera followed a similar pattern of relative abundances in the rumen and in the colon. Indeed, about half (17 taxa) of the genera decreased in relative abundance in both the rumen and the colon after calving. These included Ruminococcaceae (groups NK4A214, UCG-010, and unclassified), Clostridiales (unclassified), Erysipelotrichaceae (unclassified), Clostridia (unclassified), Flexilinea, Rikenellaceae (unclassified), and Saccharofermentans. However, only about

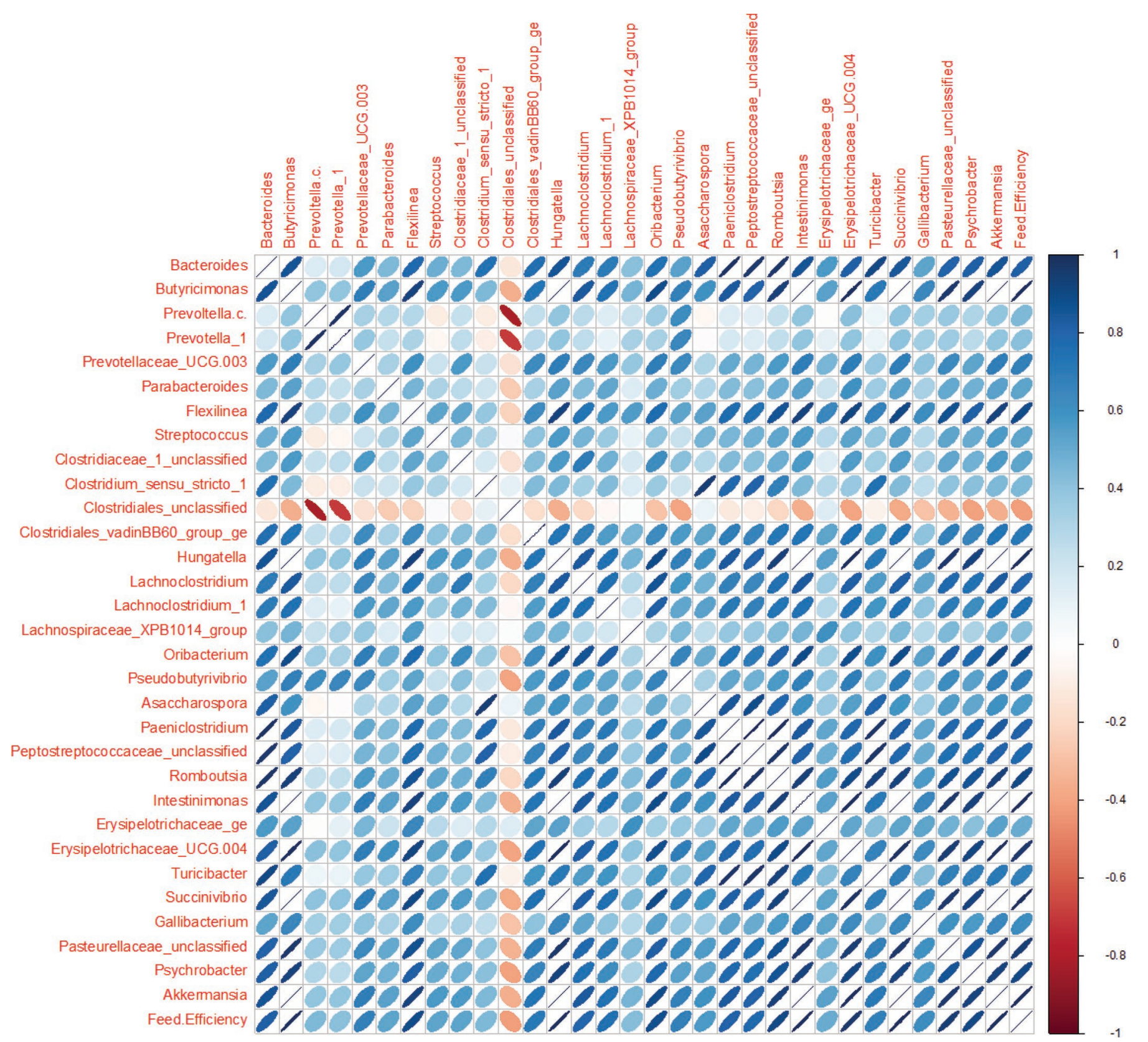

Figure 9. Correlation of ruminal genera that were significantly $(P<0.05)$ associated with feed efficiency. 
one-fourth of the detected genera, including Muribaculaceae (unclassified), Lachnospiraceae (unclassified), Lachnospiraceae (group NK3A20), Coprococcus (group 1), Atopobiaceae (unclassified), Syntrophococcus, Erysipelotrichaceae (group UCG-007), Lachnospiraceae (unclassified), and Sharpea, which increased in relative abundance in the rumen after calving, also increased in the colon. This observation might be due, in part, to the type of substrate consumed by the animal, which is partially fermented in the rumen and a fraction of it reaches the large intestine where it may foster the growth of similar genera as in the rumen.

\section{Rumen Microbiota and Productive Traits}

As reported by Bach et al. (2018), DMI of the cows in this study during the first 21 DIM was greater $(P<$ $0.05)$ in LY than in control cows. Figure 8 depicts the significant $(P<0.05)$ correlation matrix between relative abundances of selected genera in the rumen and feed intake after calving. Clostridiales (unclassified), Marvinbryantia, Ruminococcaceae (group NK4A214), Saccharofermentans, Defluviitaleaceae (group UCG-01), Anaerovorax, Lachnospiraceae (group UCG-008), Acetitomaculum, and Ruminococcaceae (group UCG-005) were all positively associated $(P<0.05)$ with postcalving DMI. On the other hand, relative abundances of Butyricimonas, Flexilinea, Hungatella, Intestinimonas, Succinivibrio, Pasteurellaceae (unclassified), Akkermansia, Erysipelotrichaceae (group UCG-004), Psychrobacter, Prevotella, Oribacterium, Prevotellaceae (group YAB2003), Romboutsia, and Prevotella (group 1) were negatively correlated with DMI after calving.

Despite the associations between several genera and DMI, the only genera whose relative abundance in the rumen was associated with milk yield was assigned to the order Gastranaerophilales, which showed a negative correlation $(\mathrm{r}=-0.45 ; P<0.05)$. Interestingly, Gastranaerophilales has also been associated with poor growth performance in lambs (Perea et al., 2017).

Figure 9 depicts the significant $(P<0.05)$ correlation matrix between relative abundance of genera in the rumen and feed efficiency. All genera in Figure 9 were positively correlated with feed efficiency with the exception of Clostridiales (unclassified), which was positively associated with DMI, and thus, the decreased feed efficiency could be just a reflection of increased intake. Similarly, among the genera positively correlated with feed efficiency, Butyricimonas, Hungatella, Intestinimonas, Succinivibrio, and Akkermansia had the strongest correlation (Figure 9) and were all negatively correlated with DMI (Figure 8). These findings would indicate, that at this stage of lactation (first 21 DIM), changes in feed efficiency associated with specific bacterial communities in the rumen, are mainly linked with changes in DMI. At this stage of lactation, promoting feed intake is actually more important than maximizing feed efficiency to prevent metabolic upsets. However, whether the increase in DMI observed herein in LY cows was due to changes in rumen microbiota or the changes in rumen microbiota were consequence of increased DMI is unknown. At later stages of lactation, Jewell et al. (2015) reported positive correlations between feed efficiency and Lachnospiraceae and negative correlations with Christensenellaceae, Fibrobacteraceae, Paraprevotellaceae, and Ruminococcaceae. Similarly, Delgado et al. (2019) reported positive correlations between feed efficiency and Coprococcus, Lachnospira, and Prevotella relative abundance in the rumen, and negative correlations between feed efficiency and Ruminococcus and Methanobrevibacter relative abundances in the rumen of cows between 60 and 120 DIM. But, in the current study, with cows in early lactation, Lachnospiraceae and Ruminococcaceae were positively correlated with DMI (but not with feed efficiency).

\section{Colon Microbiota and Productive Traits}

The relative abundances of the genera Coprococcus 1 and Acetitomaculum were positively correlated with DMI, whereas the relative abundances of Rikenellaceae (group RC9) and Ruminiclostridium (group 9) in the colon were negatively associated with DMI after calving (Figure 10). It is interesting to note that none of these genera were associated with feed efficiency, and

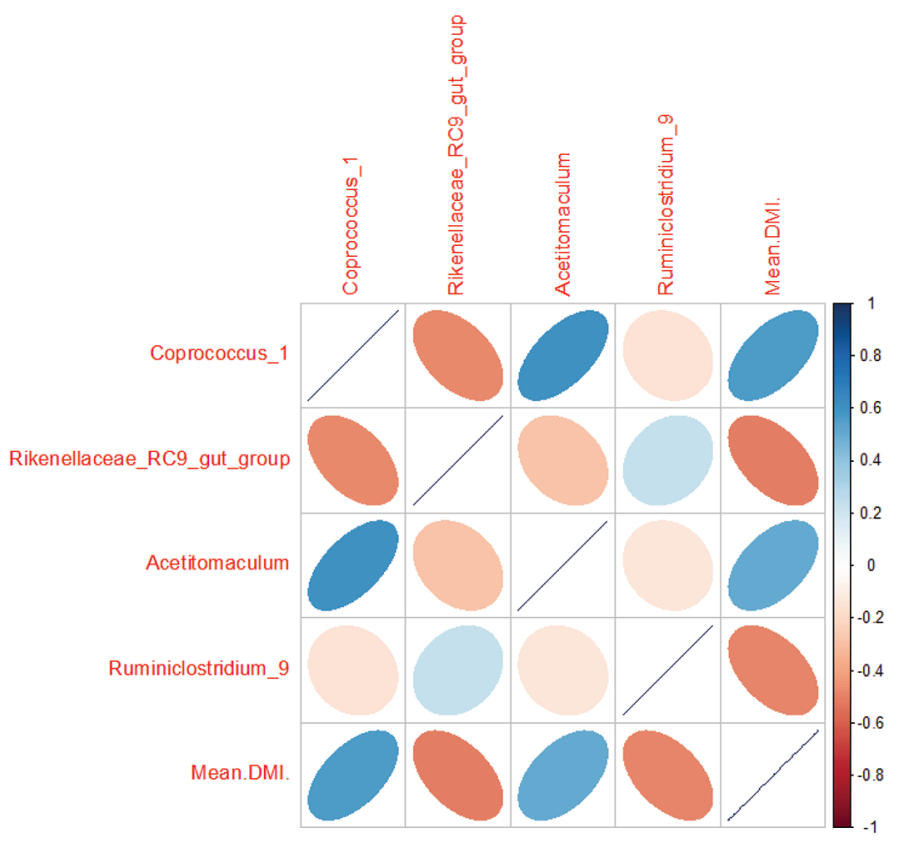

Figure 10. Correlation of genera in the colon that were significantly $(P<0.05)$ associated with DMI after calving. 

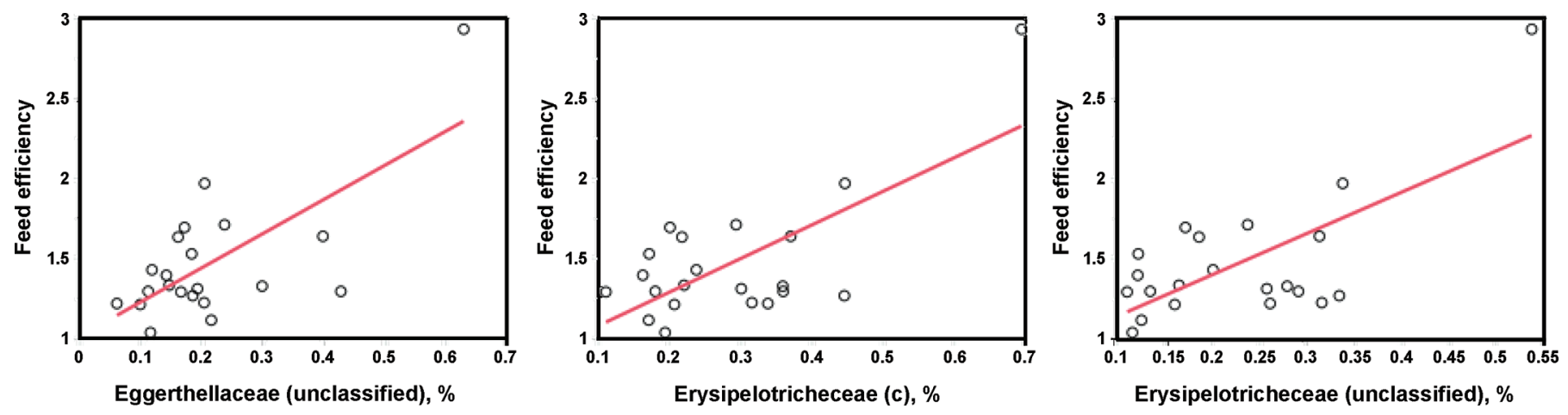
ing.

Figure 11. Correlation between the relative abundance (\%) of selected genera in the colon $14 \mathrm{~d}$ before calving and feed efficiency after calv-

thus their association with DMI was likely unassociated with milk yield. In fact, no significant associations were observed between the different genera detected in the colon and milk yield. Prevotellaceae (group Ga6A1) was the only taxon whose relative abundance in the colon was positively associated $(\mathrm{r}=0.56 ; P<0.05)$ with feed efficiency.

\section{Rumen and Colon Microbiota Precalving and Productive Traits Postcalving}

Prevotella $7(\mathrm{r}=-0.74 ; P<0.01)$ and Ruminobacter $(\mathrm{r}=-0.77 ; P<0.01)$ were the only 2 genera whose relative abundances in the rumen $14 \mathrm{~d}$ precalving were negatively correlated with DMI postcalving. Interestingly, the relative abundances of the same 2 genera (Prevotella 7 and Ruminobacter) in the rumen were also negatively correlated $(\mathrm{r}=-0.69$ and -0.68 , respectively; $P<0.01$ ) with milk yield after calving. However, these 2 genera were present in small relative abundances $(<0.01 \%$ in both cases) in the rumen before calving, and thus the hypothesis that they could play a causal role determining DMI postcalving should be further evaluated.

In the colon, the relative abundance of Parabacteroides $14 \mathrm{~d}$ before calving was negatively correlated $(\mathrm{r}=$ $-0.71 ; P<0.01)$ with milk yield after calving, and the relative abundances of Eggerthellaceae (unclassified) and Erysipelotrichaceae (group c) and unclassified were positively correlated $(0.70,0.71$, and 0.70 , respectively; $P<0.01$ ) with feed efficiency (Figure 11), with no genus showing a correlation with DMI postcalving. However, the relative abundance of Parabacteroides in the colon $14 \mathrm{~d}$ before calving was about $0.05 \%$, and that of Eggerthellaceae and Erysipelotrichaceae was approximately $0.5 \%$. Nevertheless, it is important to note that LY supplementation doubled $(P<0.05)$ the relative abundance of Eggerthellaceae in the colon at $-14,7$, and $21 \mathrm{~d}$ relative to calving.

\section{CONCLUSIONS}

During the transition from the dry period to the lactation period, the rumen experiences a transient, but important, loss of microbial diversity after calving, and the recolonization process that takes place does not appear to involve the same bacterial members. On the other hand, the microbial diversity in the colon decreases after calving and remains low at least until $21 \mathrm{~d}$ postcalving. Most of the effects of live yeast supplementation on rumen microbiota are observed before calving, whereas in the colon, the changes are more moderate but consistent and independent of the stage of production. The taxonomic diversity of the rumen after calving is more associated with feed intake, milk yield, and feed efficiency than that of the colon. However, the composition of the colon microbiota before calving is more associated with feed efficiency after calving than that found in the rumen.

\section{ACKNOWLEDGMENTS}

We thank Lallemand Animal Nutrition (Blagnac, France) for partially funding this work. The Centres de Recerca de Catalunya program from Generalitat de Catalunya (Barcelona, Catalonia) is also acknowledged for supporting this research.

\section{REFERENCES}

Abe, K., A. Ueki, Y. Ohtaki, N. Kaku, K. Watanabe, and K. Ueki. 2012. Anaerocella delicata gen. nov., sp. nov., a strictly anaerobic bacterium in the phylum Bacteroidetes isolated from a methanogenic reactor of cattle farms. J. Gen. Appl. Microbiol. 58:405-412.

Aguerre, M. J., M. A. Wattiaux, J. M. Powell, G. A. Broderick, and C. Arndt. 2011. Effect of forage-to-concentrate ratio in dairy cow diets on emission of methane, carbon dioxide, and ammonia, lactation performance, and manure excretion. J. Dairy Sci. 94:30813093. https://doi.org/10.3168/jds.2010-4011.

AOAC. 1999. Official Methods of Analysis. 15th ed. Association of Official Analytical Chemists, Arlington, VA. 
Atarashi, K., T. Tanoue, T. Shima, A. Imaoka, T. Kuwahara, Y. Momose, G. Cheng, S. Yamasaki, T. Saito, Y. Ohba, T. Taniguchi, K. Takeda, S. Hori, I. I. Ivanov, Y. Umesaki, K. Itoh, and K. Honda. 2011. Induction of colonic regulatory $\mathrm{T}$ cells by indigenous clostridium species. Science 331:337-341.

Bach, A., I. Guasch, G. Elcoso, F. Chaucheyras-Durand, M. Castex, F. Fàbregas, E. Garcia-Fruitos, and A. Aris. 2018. Changes in gene expression in the rumen and colon epithelia during the dry period through lactation of dairy cows and effects of live yeast supplementation. J. Dairy Sci. 101:2631-2640. https://doi.org/10 $.3168 /$ jds.2017-13212.

Bach, A., C. Iglesias, and I. Busto. 2004. Technical note: A computerized system for monitoring feeding behavior and individual feed intake of dairy cattle. J. Dairy Sci. 87:4207-4209. https://doi.org/ 10.3168/jds.S0022-0302(04)73565-1.

Bach, A., C. Iglesias, and M. Devant. 2007. Daily rumen pH pattern of loose-housed dairy cattle as affected by feeding pattern and live yeast supplementation. Anim. Feed Sci. Technol. 136:146-153. https://doi.org/10.1016/j.anifeedsci.2006.09.011.

Bach, A., I. K. Yoon, M. D. Stern, H. G. Jung, and H. Chester-Jones. 1999. Effects of type of carbohydrate supplementation to lush pasture on microbial fermentation in continuous culture. J. Dairy Sci. 82:153-160. https://doi.org/10.3168/jds.S0022-0302(99)75219-7.

Benjamini, Y., and Y. Hochberg. 1995. Controlling the false discovery rate: A practical and powerful approach to multiple testing. J. R. Stat. Soc. B 57:289-300.

Bolger, A. M., M. Lohse, and B. Usadel. 2014. Trimmomatic: A flexible trimmer for Illumina sequence data. Bioinformatics 30:21142120. https://doi.org/10.1093/bioinformatics/btu170.

Castro-Carrera, T., P. G. Toral, P. Frutos, N. R. McEwan, G. Hervás, L. Abecia, E. Pinloche, S. E. Girdwood, and A. Belenguer. 2014. Rumen bacterial community evaluated by 454 pyrosequencing and terminal restriction fragment length polymorphism analyses in dairy sheep fed marine algae. J. Dairy Sci. 97:1661-1669. https:// doi.org/10.3168/jds.2013-7243.

Chao, A. 1984. Non-parametric estimation of the number of classes in a population. Scand. J. Stat. 11:265-270.

Chaucheyras-Durand, F., G. Fonty, G. Bertin, M. Théveniot, and P. Gouet. 1998. Fate of Levucell@ SC I-1077 yeast additive during digestive transit in lambs. Reprod. Nutr. Dev. 38:275-280.

Chaucheyras-Durand, F., N. D. Walker, and A. Bach. 2008. Effects of active dry yeasts on the rumen microbial ecosystem: Past, present and future. Anim. Feed Sci. Technol. 145:5-26. https://doi.org/10 .1016/j.anifeedsci.2007.04.019.

Clavel, T., D. Borrmann, A. Braune, J. Doré, and M. Blaut. 2006. Occurrence and activity of human intestinal bacteria involved in the conversion of dietary lignans. Anaerobe 12:140-147.

Cotta, M., and R. Forster. 2006. The family Lachnospiraceae, including the genera Butyrivibrio, Lachnospira and Roseburia. The Prokaryotes 4:1002-1021. https://doi.org/10.1007/0-387-30744-3.

De Ondarza, M. B., C. J. Sniffen, L. Dussert, E. Cheveaux, J. Sullivan, and N. Walker. 2010. Case study: Multiple-Study analysis of the effect of live yeast on milk yield, milk component content and yield, and feed efficiency. Prof. Anim. Sci. 26:661-666. https://doi .org/10.15232/S1080-7446(15)30664-1.

Dehority, B. A. 2003. Rumen Microbiology. Nottingham University Press.

Delgado, B., A. Bach, I. Guasch, C. González, G. Elcoso, J. E. Pryce, and O. González-Recio. 2019. Whole rumen metagenome sequencing allows classifying and predicting feed efficiency and intake levels in cattle. Sci. Rep. 9:11. https://doi.org/10.1038/s41598-018 $-36673-\mathrm{w}$.

Deusch, S., A. Camarinha-Silva, J. Conrad, U. Beifuss, M. Rodehutscord, and J. Seifert. 2017. A structural and functional elucidation of the rumen microbiome influenced by various diets and microenvironments. Front. Microbiol. 8:1605. https://doi.org/10 $.3389 /$ fmicb.2017.01605.

Devlin, A. S., and M. A. Fischbach. 2015. A biosynthetic pathway for a prominent class of microbiota-derived bile acids. Nat. Chem. Biol. 11:685-690.
DeVries, T. J., and E. Chevaux. 2014. Modification of the feeding behavior of dairy cows through live yeast supplementation. J. Dairy Sci. 97:6499-6510. https://doi.org/10.3168/jds.2014-8226.

Edgar, R. C., B. J. Haas, J. C. Clemente, C. Quince, and R. Knight. 2011. UCHIME improves sensitivity and speed of chimera detection. Bioinformatics 27:2194-2200. https://doi.org/10.1093/ bioinformatics/btr381.

Fernando, S. C., H. T. Purvis, F. Z. Najar, L. O. Sukharnikov, C. R. Krehbiel, T. G. Nagaraja, B. A. Roe, and U. DeSilva. 2010. Rumen microbial population dynamics during adaptation to a highgrain diet. Appl. Environ. Microbiol. 76:7482-7490. https://doi .org/10.1128/AEM.00388-10.

Fomenky, B. E., J. Chiquette, N. Bissonnette, G. Talbot, P. Y. Chouinard, and E. M. Ibeagha-Awemu. 2017. Impact of Saccharomyces cerevisiae boulardii CNCMI-1079 and Lactobacillus acidophilus BT1386 on total lactobacilli population in the gastrointestinal tract and colon histomorphology of Holstein dairy calves. Anim. Feed Sci. Technol. 234:151-161. https://doi.org/10.1016/j .anifeedsci.2017.08.019.

Forsberg, C. W. K. J. C., and B. A. White. 1997. Polysaccharide degradation in the rumen and large intestine. Pages 319-379 in Gastrointestinal Microbiology. R. I. Mackie and B. A. White, ed. Chapman and Hall, New York, NY.

Fouts, D. E., S. Szpakowski, J. Purushe, M. Torralba, R. C. Waterman, M. D. MacNeil, L. J. Alexander, and K. E. Nelson. 2012. Next generation sequencing to define prokaryotic and fungal diversity in the bovine rumen. PLoS One 7:e48289. https://doi.org/10 $.1371 /$ journal.pone.0048289.

Goodrich, J. K., J. L. Waters, A. C. Poole, J. L. Sutter, O. Koren, R. Blekhman, M. Beaumont, W. Van Treuren, R. Knight, J. T. Bell, T. D. Spector, A. G. Clark, and R. E. Ley. 2014. Human genetics shape the gut microbiome. Cell 159:789-799. https://doi.org/10 .1016/j.cell.2014.09.053.

Harris, S. C., S. Devendran, C. Méndez-García, S. M. Mythen, C. L. Wright, C. J. Fields, A. G. Hernández, I. Cann, P. B. Hylemon, and J. M. Ridlon. 2018. Bile acid oxidation by Eggerthella lento strains C592 and DSM 2243. Gut Microbes 9:523-539. https://doi .org/10.1080/19490976.2018.1458180.

Henderson, G., F. Cox, S. Ganesh, A. Jonker, W. Young, Global Rumen Census Collaborators, and P. H. Janssen. 2015. Rumen microbial community composition varies with diet and host, but a core microbiome is found across a wide geographical range. Sci. Rep. 5:14567. https://doi.org/10.1038/srep14567.

Humer, E., K. Ghareeb, H. Harder, E. Mickdam, A. Khol-Parisini, and Q. Zebeli. 2015. Peripartal changes in reticuloruminal $\mathrm{pH}$ and temperature in dairy cows differing in the susceptibility to subacute rumen acidosis. J. Dairy Sci. 98:8788-8799. https://doi.org/ $10.3168 /$ jds.2015-9893.

Jenkins, S. N., I. S. Waite, J. Mansfield, J. C. Kim, and J. R. Pluske. 2015. Relationships between diets different in fibre type and content with growth, Escherichia coli shedding, and faecal microbial diversity after weaning. Anim. Prod. Sci. 55:1451.

Jeong, J. Y., H. D. Park, K. H. Lee, H. Y. Weon, and J. O. Ka. 2011. Microbial community analysis and identification of alternative host-specific fecal indicators in fecal and river water samples using pyrosequencing. J. Microbiol. 49:585-594.

Jewell, K. A., C. A. McCormick, C. L. Odt, P. J. Weimer, and G. Suen. 2015. Ruminal bacterial community composition in dairy cows is dynamic over the course of two lactations and correlates with feed efficiency. Appl. Environ. Microbiol. 81:4697-4710. https://doi.org/10.1128/AEM.00720-15.

Jiang, Y., I. M. Ogunade, K. G. Arriola, M. Qi, D. Vyas, C. R. Staples, and A. T. Adesogan. 2017a. Effects of the dose and viability of Saccharomyces cerevisiae. 2. Ruminal fermentation, performance of lactating dairy cows, and correlations between ruminal bacteria abundance and performance measures. J. Dairy Sci. 100:81028118. https://doi.org/10.3168/jds.2016-12371.

Jiang, Y., I. M. Ogunade, S. Qi, T. J. Hackmann, C. R. Staples, and A. T. Adesogan. 2017b. Effects of the dose and viability of Saccharomyces cerevisiae. 1. Diversity of ruminal microbes as analyzed 
by Illumina MiSeq sequencing and quantitative PCR. J. Dairy Sci. 100:325-342. https://doi.org/10.3168/jds.2016-11263.

Jouany, J. P. 2006. Optimizing rumen functions in the close-up transition period and early lactation to drive dry matter intake and energy balance in cows. Anim. Reprod. Sci. 96:250-264. https:// doi.org/10.1016/j.anireprosci.2006.08.005.

Kim, M., J. Kim, L. A. Kuehn, J. L. Bono, E. D. Berry, N. Kalchayanand, H. C. Freetly, A. K. Benson, and J. E. Wells. 2014. Investigation of bacterial diversity in the feces of cattle fed different diets. J. Anim. Sci. 92:683-694.

Klindworth, A., E. Pruesse, T. Schweer, J. Peplies, C. Quast, M. Horn, and F. O. Glöckner 2013. Evaluation of general 16S ribosomal RNA gene PCR primers for classical and next-generation sequencing-based diversity studies. Nucleic Acids Res. 7:41:e1. https://doi .org/10.1093/nar/gks808.

Kong, Y., R. Teather, and R. Forster. 2010. Composition, spatial distribution, and diversity of the bacterial communities in the rumen of cows fed different forages. FEMS Microbiol. Ecol. 74:612-622.

Lima, F. S., G. Oikonomou, S. F. Lima, M. L. S. Bicalho, E. K. Ganda, J. C. de Oliveira Filho, G. Lorenzo, P. Trojacanec, and R. C. Bicalho. 2015. Prepartum and postpartum rumen fluid microbiomes: characterization and correlation with production traits in dairy cows. Appl. Environ. Microbiol. 81:1327-1337. https://doi .org/10.1128/AEM.03138-14.

McMurdie, P. J., and S. Holmes. 2013. phyloseq: An R Package for Reproducible Interactive Analysis and Graphics of Microbiome Census Data. PLoS One 8:e61217. https://doi.org/10.1371/journal .pone.0061217.

Morotomi, M., F. Nagai, and Y. Watanabe. 2012. Description of Christensenella minuta gen. nov., sp. nov., isolated from human faeces, which forms a distinct branch in the order Clostridiales, and proposal of Christensenellaceae fam. nov. Int. J. Syst. Evol. Microbiol. 62:144-149. https://doi.org/10.1099/ijs.0.026989-0.

Nagaraja, T. G., and E. C. Titgemeyer. 2007. Ruminal acidosis in beef cattle: The current microbiological and nutritional outlook. J. Dairy Sci. 90(Suppl. 1):E17-E38.

NRC. 2001. Nutrient Requirements of Dairy Cattle. 7th rev. ed. National Academy Press, Washington, DC.

Perea, K., K. Perz, S. K. Olivo, A. Williams, M. Lachman, S. L. Ishaq, J. Thomson, and C. J. Yeoman. 2017. Feed efficiency phenotypes in lambs involve changes in ruminal, colonic, and small-intestinelocated microbiota. J. Anim. Sci. 95:2585-2592. https://doi.org/ $10.2527 /$ jas.2016.1222.

Petri, R. M., T. Schwaiger, G. B. Penner, K. A. Beauchemin, R. J. Forster, J. J. McKinnon, and T. A. McAllister. 2013. Characterization of the core rumen microbiome in cattle during transition from forage to concentrate as well as during and after an acidotic challenge. PLoS One 8:e83424. https://doi.org/10.1371/journal pone.0083424.

Pitta, D. W., S. Kumar, B. Vecchiarelli, D. J. Shirley, K. Bittinger, L. D. Baker, J. D. Ferguson, and N. Thomsen. 2014. Temporal dynamics in the ruminal microbiome of dairy cows during the transition period. J. Anim. Sci. 92:4014-4022. https://doi.org/10 $.2527 /$ jas.2014-7621.

Quast, C., E. Pruesse, P. Yilmaz, J. Gerken, T. Schweer, P. Yarza, J. Peplies, and F. O. Glöckner. 2013. The SILVA ribosomal RNA gene database project: Improved data processing and web-based tools. Nucleic Acids Res. 41:D590-D596.

R Core Team. 2018. R: A language and environment for statistical computing. R Foundation for Statistical Computing, Vienna, Austria. http://www.R-project.org/.

Ritchie, M. E., B. Phipson, D. Wu, Y. Hu, C. W. Law, W. Shi, and G. K. Smyth. 2015. Limma powers differential expression analyses for RNA-sequencing and microarray studies. Nucleic Acids Res. 43:e47.

Russell, J. B., and D. B. Dombrowski. 1980. Effect of $\mathrm{pH}$ on the efficiency of growth by pure cultures of rumen bacteria in continuous culture. Appl. Environ. Microbiol. 39:604-610.

Schloss, P. D., S. L. Westcott, T. Ryabin, J. R. Hall, M. Hartmann, E. B. Hollister, R. A. Lesniewski, B. B. Oakley, D. H. Parks, C.
J. Robinson, J. W. Sahl, B. Stres, G. G. Thallinger, D. J. Van Horn, and C. F. Weber. 2009. Introducing mothur: Open-source, platform-independent, community-supported software for describing and comparing microbial communities. Appl. Environ. Microbiol. 75:7537-7541.

Selma, M. V., D. Beltrán, R. García-Villalba, J. C. Espín, and F. A. Tomás-Barberán. 2014. Description of urolithin production capacity from ellagic acid of two human intestinal Gordonibacter species. Food Funct. 5:1779-1784. https://doi.org/10.1039/c4fo00092g.

Smith, B., and J. B. Wilson. 1996. A consumer's guide to evenness indices. Oikos 76:70-82.

Stevenson, D. M., and P. J. Weimer. 2007. Dominance of Prevotella and low abundance of classical ruminal bacterial species in the bovine rumen revealed by relative quantification real-time PCR. Appl. Microbiol. Biotechnol. 75:165-174.

Sun, L., M. Toyonaga, A. Ohashi, N. Matsuura, D. M. Tourlousse, X.Y. Meng, H. Tamaki, S. Hanada, R. Cruz, T. Yamaguchi, and Y. Sekiguchi. 2016. Isolation and characterization of Flexilinea flocculi gen. nov., sp. nov., a filamentous, anaerobic bacterium belonging to the class Anaerolineae in the phylum Chloroflexi. Int. J. Syst. Evol. Microbiol. 66:988-996. https://doi.org/10.1099/ijsem .0 .000822

Terré, M., G. Maynou, A. Bach, and M. Gauthier. 2015. Effect of Saccharomyces cerevisiae CNCM I-1077 supplementation on performance and rumen microbiota of dairy calves. Prof. Anim. Sci. 31:153-158. https://doi.org/10.15232/pas.2014-01384.

Thrune, M., A. Bach, M. Ruiz Moreno, M. D. Stern, and J. G. Linn. 2009. Effects of Saccharomyces cerevisiae on ruminal $\mathrm{pH}$ and microbial fermentation in dairy cows. Livest. Sci. 124:261-265. https: //doi.org/10.1016/j.livsci.2009.02.007.

Tigchelaar, E. F., M. J. Bonder, S. A. Jankipersadsing, J. Fu, C Wijmenga, and A. Zhernakova. 2016. Gut microbiota composition associated with stool consistency. Gut 65:540-542.

Van Soest, P. J.. J. B. Robertson, and B. A. Lewis. 1991. Methods for dietary fiber, neutral detergent fiber and non-starch polysaccharide in relation to animal nutrition. J. Dairy Sci. 74:3583-3597. https://doi.org/10.3168/jds.S0022-0302(91)78551-2.

Větrovský, T., and P. Baldrian. 2013. The variability of the $16 \mathrm{~S}$ rRNA gene in bacterial genomes and its consequences for bacterial community analyses. PLoS One 8:e57923. https://doi.org/10.1371/ journal.pone.0057923.

Wang, Q., G. M. Garrity, J. M. Tiedje, and J. R. Cole. 2007. Naive Bayesian classifier for rapid assignment of rRNA sequences into the new bacterial taxonomy. Appl. Environ. Microbiol. 73:52615267. https://doi.org/10.1128/AEM.00062-07.

Westcott, S. L., and P. D. Schloss. 2017. OptiClust, an improved method for assigning amplicon-based sequence data to operational taxonomic units. MSphere 2:e0073-e17. https://doi.org/10.1128/ mSphereDirect.00073-17.

Yeoman, C. J., S. L. Ishaq, E. Bichi, S. K. Olivo, J. Lowe, and B. M. Aldridge. 2018. Biogeographical differences in the influence of maternal microbial sources on the early successional development of the bovine neonatal gastrointestinal tract. Sci. Rep. 8:3197. https: //doi.org/10.1038/s41598-018-21440-8.

Zened, A., S. Combes, L. Cauquil, J. Mariette, C. Klopp, O. Bouchez, A. Troegeler-Meynadier, and F. Enjalbert. 2013. Microbial ecology of the rumen evaluated by 454 GS FLX pyrosequencing is affected by starch and oil supplementation of diets. FEMS Microbiol. Ecol. 83:504-514.

Zhou, M., E. Hernandez-Sanabria, and L. L. Guan. 2009. Assessment of the microbial ecology of ruminal methanogens in cattle with different feed efficiencies. Appl. Environ. Microbiol. 75:6524-6533. https://doi.org/10.1128/AEM.02815-08.

Zhu, Z., L. Kristensen, G. F. Difford, M. Poulsen, S. J. Noel, W. A. Al-Soud, S. J. Sørensen, J. Lassen, P. Løvendahl, and O. Højberg. 2018. Changes in rumen bacterial and archaeal communities over the transition period in primiparous Holstein dairy cows. J. Dairy Sci. 101:9847-9862. https://doi.org/10.3168/jds.2017-14366. 